\title{
A framework for conceptualizing and assessing the resilience of essential services produced by socio-technical systems
}

\author{
$\underline{S u s a r a}$ E. van der Merwe $^{1,2}$, Reinette Biggs ${ }^{1,3}$ and Rika Preiser $^{1}$
}

\begin{abstract}
Essential services such as electricity are critical to human well-being and the functioning of modern society. These services are produced by complex adaptive socio-technical systems and emerge from the interplay of technical infrastructure with people and governing institutions. Ongoing global changes such as urbanization and increasing prevalence of extreme weather events are generating much interest in strategies for building the resilience of essential services. However, much of the emphasis has been on reliable and resilient technical infrastructure. This focus is insufficient; resilience also needs to be built into the human and institutional processes within which these technical systems are embedded. Here, we propose a conceptual framework, based on a complex adaptive systems perspective, that identifies four key domains that require investment to build the resilience of essential services. This framework addresses both the technical and social components of the socio-technical systems that underlie essential services and incorporates specified and general resilience considerations. The framework can be used to guide resilience assessments and to identify strategies for building resilience across different organizational levels.
\end{abstract}

Key Words: complex adaptive systems; critical infrastructure; electricity supply; essential services; resilience assessment; socio-technical system

\section{INTRODUCTION}

Modern society depends on a wide range of services being resilient in the face of disruption and rapid global change (Holling 2001, UNISDR 2015). These services include ecosystem services produced by social-ecological systems, as well as technologically mediated essential services such as electricity, water, and sanitation. Similar to ecosystem services, disruption in essential services can cause ripple effects, with considerable social consequence (Schulman et al. 2004, Rose et al. 2007, Pescaroli and Alexander 2015), and can escalate to disaster if it exceeds the ability of the affected community to cope (UNISDR 2009, 2015). Along with efforts to foster resilience of ecosystem services, building resilience of essential services is critically needed (La Porte 2006), accompanied by practical frameworks and approaches to better understand and assess the resilience of such services.

Essential services are produced by complex adaptive sociotechnical systems (Varga 2015), which are embedded within broader social-ecological systems (Folke 2006, STAP 2015). Essential services are coproduced through the interplay of technology and social institutions, or hard and soft infrastructure, that compose socio-technical systems. Hard infrastructure refers to physical technical assets and systems, whereas soft infrastructure refers to social systems such as institutions, users, rules, and regulations (UNESCAP 2013). Most of the current resilience emphasis around essential services focuses on development, maintenance, and protection of the hard infrastructure, rather than assurance of the service itself (Auerswald et al. 2006, La Porte 2006). Investments in hard infrastructure ought to be accompanied by investments in soft infrastructure to ensure resilient service delivery. In the emergency preparedness and disaster management communities, it is increasingly recognized that continuity of essential services requires a focus on the broad-based resilience capabilities of communities, the private sector, and all levels of government (DHS 2010, NIAC 2010, FEMA 2015).

Ensuring the resilience of electricity supply is of particular interest to government administrators (Grid Resiliency Task Force 2012, Executive Office of the President 2013, City of New York 2013, NAS 2017). Electricity supply is considered a foundational service because many other layers of critical infrastructure and the essential services derived from them (such as water supply) depend on electricity (Koester and Cohen 2012, Jeschonnek et al. 2016). Like the socio-technical systems that produce other essential services, the electricity supply system is a complex adaptive system susceptible to disruption (Amin 2015). To ensure resilience, the interlinked social and technical parts of the system continuously have to rebound from, adapt to, and transform amid the many environmental, technical, and social risks factors that can disrupt supply.

In common usage, resilience refers to the ability to bounce back or spring back into shape following a disruption. As a systemslevel characteristic, resilience is an emergent property of complex adaptive systems (Cork 2011, Aldunce et al. 2015) and refers to the capacity of a system to sustain core functions in the face of disruption and change (Folke et al. 2010, Biggs et al. 2012). Resilience can be used in either a descriptive or a normative sense. From a descriptive perspective, the concept is neutral and refers to the persistence of the core functions and identity of a system (Walker et al. 2004, Cumming et al. 2005), which can be either desirable or undesirable. Examples of undesirable resilient systems include poverty traps and organized crime (Barrett and Constas 2014, Dahlberg 2015). More recently, there has been a groundswell of interest in the normative use of resilience as an approach for managing complex adaptive systems toward

${ }^{1}$ Centre for Complex Systems in Transition, Stellenbosch University, South Africa, ${ }^{2}$ Enterprise Resilience Department, Risk \& Sustainability Group, Eskom, South Africa, ${ }^{3}$ Stockholm Resilience Centre, Stockholm University, Sweden 
desirable outcomes (Biggs et al. 2012, Seville et al. 2015, Folke 2016). From a normative perspective, resilience is not merely the ability to sustain core functions, but to sustain specific outcomes such as continued production of specific ecosystem (Biggs et al. 2015, Folke et al. 2016) or essential services. This ability may entail bouncing back after a disruption, but could also involve systemic transformation and bouncing forward to a position better than before (Boin and Van Eeten 2013, Weichselgartner and Kelman 2015).

Here, we propose a framework to conceptualize and assess the resilience of essential services using a complex adaptive systems perspective. For our purposes, we apply resilience normatively and define resilience of essential services as the capacity of complex adaptive socio-technical systems to sustain the production of essential services in the face of disruption and ongoing social, technological, and environmental change. The framework we propose draws on and integrates work on resilience from several different disciplinary traditions, particularly work on social-ecological systems (Biggs et al. 2015, Folke et al. 2016), research on the resilience of engineered systems (Madni and Jackson 2009, Park et al. 2013), and organizational resilience (Weick et al. 1999, Linnenluecke and Griffiths 2012), as well as practical policy guidance that focuses on critical social responses from community resilience (Cabinet Office 2011, NIST 2016a). We integrate these different strands of work based on a common underlying view of these problems as complex adaptive systems problems.

The framework we propose draws on an interdisciplinary synthesis of literature, as well as practical experience of conducting resilience assessments to electricity supply in Eskom Holdings, the South African national electrical utility. The South African experience is emblematic of the challenges facing electric utility providers, particularly in developing countries. By focusing on a clearly defined system, we aim to explore how the resilience of essential services that underpin key functions in modern societies can be enhanced. We suggest that this framework can be applied to other essential services and, with some modification, can also advance the understanding of social-ecological resilience more generally.

\section{ELECTRICITY SUPPLY AS A COMPLEX ADAPTIVE SYSTEMS PROBLEM: THE CASE OF SOUTH AFRICA}

Globally, electricity supply systems face an increase in the number and severity of large-scale emergencies, often triggered by severe weather (Abi-Samra et al. 2014, Cabinet Office 2015). In emerging economies, this trend is aggravated by rapid growth in electricity demand, posing challenges for reliable service provision and constraining opportunities for social and economic development (Bocca and Mehlum 2012). In the case of South Africa, 95\% of the electricity used in the country is supplied by Eskom, a national vertically integrated generation, transmission, and distribution utility (Eskom 2016a). In a relatively short period of time, Eskom went from global power company of the year in 2001 (Khoza and Adam 2006) to no longer being able to maintain the national supply-demand balance in 2008, resulting in three weeks of nationwide rotational load shedding to deal with the shortfall (Chettiar et al. 2009). By 2014, the South African energy profile became comparable to that of China, India, and Mexico at the time, where energy shortfalls significantly constrain economic growth to meet human development needs (Bocca and Mehlum 2012).

Eskom initiated a resilience strategy in 2008 in response to growing electricity shortfalls and to deal with the new reality of regular loadshedding. Initially, the focus was only on power system resilience, but it expanded to the whole enterprise in 2013 to deal with wider business risks that were emerging. The purpose of a resilience focus is to prepare the organization to deal with business unusual. The expanded enterprise resilience focus is to ensure an integrated overview of risks and to facilitate an integrated emergency response capability to deal with systemslevel emergencies and special events such as the FIFA World Cup and national elections (Koch et al. 2013). There is a realization that traditional reductionist approaches, widely used to manage technology in the organization, are inadequate to deal with the complexity of emerging systemic problems (Guckenheimer and Ottino 2008), particularly the low-probability high-consequence risk of blackouts that Eskom has to manage.

The dynamics of complex adaptive power systems cause the systems to drift toward a critical point at which their apparent stability can abruptly change state (Dobson et al. 2007, Viejo et al. 2015). The complex intertwining of unforeseeable coincidences may cause rapidly cascading failure in the power system, and, in the worst case, results in a blackout (Bo et al. 2015), i.e., a widearea outage of long duration (NAS 2017). A blackout, in turn, normally results in further cascading failure across other interconnected and interdependent infrastructures such as water or telecommunications (Rinaldi et al. 2001, Mukhopadhyay and Hastak 2016). Widespread blackouts are low-probability highconsequence events that often result in significant social and economic impact (Bo et al. 2015). In most developed nations with their highly interconnected grids, a blackout is rapidly restored through interconnections from neighboring areas that still have power (Bo et al. 2015). However, in the case of a national blackout, none of Eskom's neighboring electricity utilities have the capacity to restart the South African power system, which highlights the importance of resilience in general, and a black-start capability in particular. However, a well-developed technical black-start plan is insufficient to ensure national resilience to a blackout incident; institutional arrangements and integrated response plans are required in partnership with priority national role players (such as fuel, water, telecommunications, and security) to effectively respond to, and deal with, the consequences of a national blackout.

Given the described situation, it is clear that a fundamental, deliberate, and transformative change is required within and among institutions at national, regional, and local levels to establish the necessary preparedness across multiple sectors. We draw on the emerging body of work on complex systems problems (Cilliers 2000, Westley et al. 2006, Allenby and Sarewitz 2011) that indicates that such transformative change can be facilitated by recognizing that problems such as sustaining electricity supply in the face of disruption and change are fundamentally complex, rather than mere technical problems. Contingency planning and response strategies need to be implemented. The capacity to prepare and respond in a coordinated fashion requires complex 
Table 1. The difference between complicated and complex adaptive systems and problems, adapted from Poli (2013).

\begin{tabular}{|c|c|c|}
\hline Feature & Complicated problems & Complex problems \\
\hline Boundary & Level 1 & Level 2 (as defined by Allenby and Sarewitz 2011) \\
\hline Causality & $\begin{array}{l}\text { Complicated problems originate } \\
\text { from causes that can be } \\
\text { individually distinguished }\end{array}$ & $\begin{array}{l}\text { Complex problems and systems result from networks of multiple interacting causes that } \\
\text { cannot be individually distinguished }\end{array}$ \\
\hline Reduction & $\begin{array}{l}\text { Problems can be addressed piece } \\
\text { by piece }\end{array}$ & $\begin{array}{l}\text { Problems must be addressed as entire systems, that is, they cannot be addressed in a } \\
\text { piecemeal way }\end{array}$ \\
\hline Linearity & $\begin{array}{l}\text { For each input to the system there } \\
\text { is a proportionate output }\end{array}$ & Small inputs may result in disproportionate effects \\
\hline Solvability & $\begin{array}{l}\text { These problems admit permanent } \\
\text { solutions }\end{array}$ & $\begin{array}{l}\text { These problems cannot be solved in full, but require systematic management. Typically, any } \\
\text { intervention merges into new problems as a result of the interventions dealing with them } \\
\text { (Poli 2013) }\end{array}$ \\
\hline Controllability & $\begin{array}{l}\text { The relevant systems can be } \\
\text { controlled }\end{array}$ & $\begin{array}{l}\text { The relevant systems cannot be controlled; the best one can do is to influence them. These } \\
\text { problems have to be engaged directly; one must learn to "dance with them" (Meadows } \\
\text { 2009:70, Poli 2013) }\end{array}$ \\
\hline
\end{tabular}

adaptive systems thinking (Cilliers 2007, Bohensky et al. 2015), which emphasizes the presence of the interlinked nature of technical and human systems, their processes of interaction, and their tendency to self-organize into different regimes or result in disorder associated with critical stability points (Holling et al. 2002, Folke 2006).

The difference between complicated and complex adaptive systems and problems is a difference of type, not of degree (Poli 2013). It is necessary to draw a clear distinction between these types of problems because the methods and approaches for understanding and managing them differ vastly (Snowden and Boone 2007, Poli 2013; Table 1). Reductionist approaches rely on problem-solving strategies that delimit reality into smaller parts and apply methodologies that aim toward predictability and control (Ramalingam et al. 2008). Such approaches assume that the nature of the problem is complicated. Reductionist approaches are inadequate to address complex problems. Complex problems require ongoing engagement and adaptation because apparent solutions often give rise to new problems (Poli 2013). Complex adaptive systems thinking explicitly considers unintended consequences, the agency of people, and unpredictable novelty (Juarrero 1999, Kurtz and Snowden 2003, Allenby and Sarewitz 2011). In reality, most problem situations contain both complicated and complex phenomena. It is essential for decision makers to make sense of the problem composition so as to apply solutions compatible with the nature of the problem at hand (Snowden and Boone 2007).

The system boundaries described by Allenby and Sarewitz (2011) are a useful guide to distinguishing between complicated and complex problems in socio-technical systems. Level 1 system boundaries are defined in terms of specific technological solutions such as electrical transformers or switchgear that aim to address a particular problem. Level 1 problems generally correspond to complicated problems that focus on hard infrastructure. However, for level 1 solutions to function, they are always embedded in level 2 systems, which incorporate the wider psychological, social, and cultural contexts that are inseparable from the technology (Allenby and Sarewitz 2011). Level 2 systems are complex adaptive systems that are susceptible to nonlinear risks and catastrophic disruption. Technical components in the power system are typically analyzed at level 1, whereas the overall electricity supply system should be recognized as a level 2 complex adaptive socio-technical system. The different types of problems described in Table 1 are thus correlated with boundary definition.

Eskom recognizes resilience as a strategic imperative (Eskom 2016a). By design, Eskom has multiple layers of defence to prevent a blackout, which are actively maintained to ensure their integrity. Even though the probability of such high-consequence events is low, Eskom is committed to establishing response preparedness and employing risk reduction measures to reduce the fallout from such eventualities (Eskom 2016b).

\section{RESILIENCE THINKING}

Resilience thinking is an application of complex adaptive systems thinking that pays specific attention to enhancing resilience. Building resilience has arisen as a response to deal with uncertainty and external risk, limited control, deep disruption, and an unpredictable future (DuPlessis VanBreda 2001, Sheffi 2005, Bhamra et al. 2011, Caldwell 2014). Resilience refers to the innate ability of complex adaptive systems to absorb disturbances or surprise and to adapt to dynamic change without losing their identity or function (Folke et al. 2002, Walker et al. 2004, Berkes 2007). The concept of resilience therefore includes interrelated aspects of persistence, adaptability, and transformability (Walker et al. 2004, Folke et al. 2010). Following this line of thinking, we define a resilient socio-technical electricity supply system from a normative perspective as one that has the emergent capability to absorb large shocks, even for low-probability high-consequence events such as a national blackout, and to continue to adapt amid ongoing changes such as climate change and urbanization while continuing to ensure reliable electricity supply in an affordable and sustainable manner.

Literature on the application of resilience distinguishes between two different types of resilience that need to be established simultaneously: specified and general resilience (Folke et al. 2010, O'Connell et al. 2015a). Specified resilience refers to the resilience of a specified part of the system to identified disruptions, whereas general resilience refers to the capacity of a system to withstand all hazards, including novel and unforeseen ones, while continuing to provide essential functions (Walker et al. 2009; Table 2). General resilience is a generic capability to cope with uncertainty 
Table 2. Characteristics of specified and general resilience.

\begin{tabular}{|c|c|c|}
\hline Characteristic & Specified resilience & General resilience \\
\hline $\begin{array}{l}\text { How to identify } \\
\text { it }\end{array}$ & $\begin{array}{l}\text { The ability to persist within a stability zone (Folke et al. 2010) } \\
\text { through anticipation strategies, being prepared, and applying } \\
\text { prevention (Comfort et al. 2001) }\end{array}$ & $\begin{array}{l}\text { An intangible emergent capacity for adaptation and transformation } \\
\text { (Folke et al. 2010) across multiple equilibria (North 1993, Caldwell } \\
\text { 2014) }\end{array}$ \\
\hline How to build it & $\begin{array}{l}\text { Can be established by following best practice, through } \\
\text { managing foreseeable risks (Garred 2013), and by how } \\
\text { infrastructure is designed, built, and maintained (NIAC 2010) }\end{array}$ & $\begin{array}{l}\text { Is nurtured through the capacity for abductive thinking and sense } \\
\text { making (Grøtan 2013) and evolutionary self-organization (Allan and } \\
\text { Bryant 2014, Scolobig et al. 2015, De Coning 2016) }\end{array}$ \\
\hline $\begin{array}{l}\text { How to sustain } \\
\text { it }\end{array}$ & $\begin{array}{l}\text { Employs single-loop learning and aims to strengthen negative } \\
\text { feedback loops (Antonacopoulou and Chiva, unpublished } \\
\text { manuscript } t^{\dagger} \text { ): to return conditions toward a predetermined } \\
\text { target, to remove deviations, and to keep operations within } \\
\text { deterministic boundaries (Weick and Sutcliffe 2007) }\end{array}$ & $\begin{array}{l}\text { Employs double-loop learning and aims to strengthen positive } \\
\text { feedback loops (Antonacopoulou and Chiva, unpublished } \\
\text { manuscript } t^{\dagger} \text { ): to self-reinforce, amplify, enhance, and stimulate } \\
\text { behaviors that enhance resilience, which includes modifying the rules } \\
\text { that drive behavior (Holman 2010) }\end{array}$ \\
\hline
\end{tabular}

and surprise and to endure novelty and instability, including multiple shocks and cascading failure (Folke et al. 2010, Walker and Salt 2012). General resilience emerges when predetermined plans are inadequate to deal with the situation at hand, and new capabilities are dynamically developed to respond (Lee et al. 2013). Resilience literature cautions that resilience investments have to be balanced across specified and general resilience because effort channeled into developing only one kind of resilience may reduce the other kind (Folke et al. 2010, Resilience Alliance 2010, Cork 2011).

Here, we apply the bifocal lens of complicated and complex problems to clarify the operational implications for building specified and general resilience. To establish specified resilience, decomposition of the system and its environment is required to determine "what" internal parts should be resilient, and against "what" external aspects of the environment this resilience is required (Carpenter et al. 2001). Although this reductionist approach is pragmatic, it employs a complicated approach to a complex system. Resilience associated with technical components can be engineered in a complicated fashion using classical reliability-oriented design (Holling 1996). Experts can follow best practice or good practice (Hummelbrunner and Jones 2013a) to establish resilience of specific parts of the system to specified shocks. However, these level 1 components can collapse when critical thresholds are exceeded in the level 2 systems context in which they are embedded (Pourbeik et al. 2006, Simone 2014). General resilience therefore needs to be established across multiple facets of the level 2 system and necessitates resilience practitioners to embrace complexity-based approaches.

A key capability that enables leaders to make sense of inherent complexity and ambiguity is sensemaking (Weick 1995), i.e., the ability to comprehend, understand, and explain what is going on (Ancona 2012). Sensemaking is an integral part of learning and consists of an ongoing action-oriented cycle of acquisition, reflection, and action that people go through to integrate experiences into their understanding of the world to inform action (Kolko 2010). Sensemaking shapes organizational behavior, i.e., how the organization makes sense of where it is and what is going on, and directly affects how the agents in the system adapt and self-organize, which, in turn, influences how the system develops (Weick 1995). Appropriate collective sensemaking is crucial to ensure resilient service delivery because it directly affects general resilience features through the effectiveness of organizational response to crisis or disruption (Casto 2014).

\section{Resilience assessment}

Along with the rapid rise in interest in fostering resilience, there has been great demand for improved approaches to assess resilience (Quinlan et al. 2015). Assessments can be distinguished based on purpose (why), target audience (for whom), level of assessment (of whom), and object of assessment (what; Terenzini 1989, Carpenter et al. 2001, Quinlan et al. 2015). Many different resilience assessment methods exist. Several approaches highlight the need for participatory approaches (Almedom et al. 2007, Pasteur 2011, O'Connell et al. 2015b, Quinlan et al. 2015). Other resilience assessment approaches distinguish between types of resilience, an evaluation of the actual resilience displayed in past incidents, or comprise indicators of adaptive management, adaptive governance, or transformative capacity (Cork 2011, Walker and Salt 2012, O'Connell et al. 2015a). A stated objective of many resilience assessments is to understand how to build resilience of some desired outcome.

Drawing on the literature from educational assessments, we distinguish between "summative assessments" that primarily aim to evaluate current levels of resilience for external reporting and benchmarking, and "formative assessments" that aim to build resilience through the assessment process itself (Table 3). Although these two objectives are not mutually exclusive, clarification of the primary purpose of a particular resilience assessment exercise can help in selecting a suitable approach. Summative assessments seek to standardize indicators for the benefit of comparison and to aggregate toward national or regional reporting of resilience (Stephenson 2010, O'Connell et al. 2015a, RESILENS 2016). Formative assessments comprise an ongoing process, not a periodic product (Black et al. 2003, Nicol and Macfarlane-Dick 2006). Such assessments entail a systematic and ongoing internal process of seeking and interpreting evidence, to participatively make sense of the current levels of system resilience, and to garner agreement to improve attainment of resilience outcomes. Formative assessments center on critical conversations among key actors in the system to enable collective sensemaking, promote commitment to resilience goals, and adaptively stimulate the emergence of resilience throughout the system. Care should be taken that the approach used does not undermine the intended outcome. When assessments for 
Table 3. Differentiation between formative and summative resilience assessments.

\begin{tabular}{ll}
\hline \hline Formative resilience assessment & Summative resilience assessment \\
\hline Can be an ongoing process & $\begin{array}{l}\text { Can be scheduled periodically } \\
\text { "Of" resilience }\end{array}$ \\
"For" a resilience outcome & Against standardized indicators decided top-down \\
To facilitate a bottom-up dialogue among actors in the system & For the purpose of producing a report for a third party \\
To diagnose where the system is in its levels of resilience & To give an account of what has been achieved \\
To agree where resilience should be strengthened & For comparison, aggregation, or benchmarking \\
Through collective action toward shared resilience goals &
\end{tabular}

enhancing resilience are conducted as punitive compliance audits, it can lead to unintended consequences and erode resilience instead of building it (Dekker and Breakey 2016).

Formative resilience assessment processes merge into a transformative assess-and-build cycle. Such assessments require direct engagement with the complex adaptive system to learn about the nature of the complex dynamics (Quinlan et al. 2015). Key actors probe the system interactively to make sense of dynamically changing feedback mechanisms, constraints, and patterns of emergence (Juarrero 1999, Walker and Salt 2006). Attention is paid to: what builds, maintains, and breaks down resilience; where undesirable resilience should be disrupted; and where desirable resilience can be enhanced (Cork 2009, Quinlan et al. 2015). The assessor is part of the complex adaptive system, and probing can affect emergence of the system in unpredictable ways. Therefore, all probes should be carefully designed as interventions to enhance resilience (Holman 2010), and every intervention to build resilience can be used as a probe to better understand the system and its resilience dynamics. This ongoing process can adaptively transform the system's resilience over time.

\section{A FRAMEWORK FOR CONCEPTUALIZING THE RESILIENCE OF ESSENTIAL SERVICES}

Building on the emerging theoretical ideas outlined above, of resilience as the emergent outcome of complex adaptive systems, and practical experiences in operationalizing resilience thinking and assessments in the context of electricity supply in South Africa, we present a framework for conceptualizing different aspects of resilience in complex adaptive socio-technical systems. To conceptualize the resilience of essential services, we juxtapose the types of resilience (specified and general) and focus of resilience investment (technology or social; Fig. 1). Although the social and technical components are interdependent, the distinction here is based on the content (Rosen 2000) and the focus of the resilience strategy (NIAC 2010). The resulting four quadrants represent different resilience domains that can serve as a guide for how to assess and build resilience of essential services:

- The "specified technical resilience" quadrant represents areas where resilience to specific risks (e.g., storms) is built into technical infrastructure to ensure that it is adequate, reliable, and secure. This quadrant focuses on building robustness into level 1 systems.

- The "specified social resilience" quadrant represents areas where resilience to specific risks (e.g., disruption to critical business processes) is established through processes and institutions in the social domain. This quadrant focuses on building specific skills, response capabilities, and plans within level 2 systems.
- The "general technical resilience" quadrant represents areas where resilience to novel and unknown risks is established through network topology or adaptive technologies that offer systems-level flexibility to enable an agile response across the system in dealing with uncertainty. This quadrant focuses on connectivity and structure of level 2 systems to ensure systems-level flexibility.

- The "general social resilience" quadrant represents areas where resilience to novel and unknown risks is established through people, processes, and institutions. This quadrant focuses on collective human agency, agility, and volition in level 2 systems.

Fig. 1. A conceptual framework for building and assessing resilience of essential services produced by socio-technical systems.

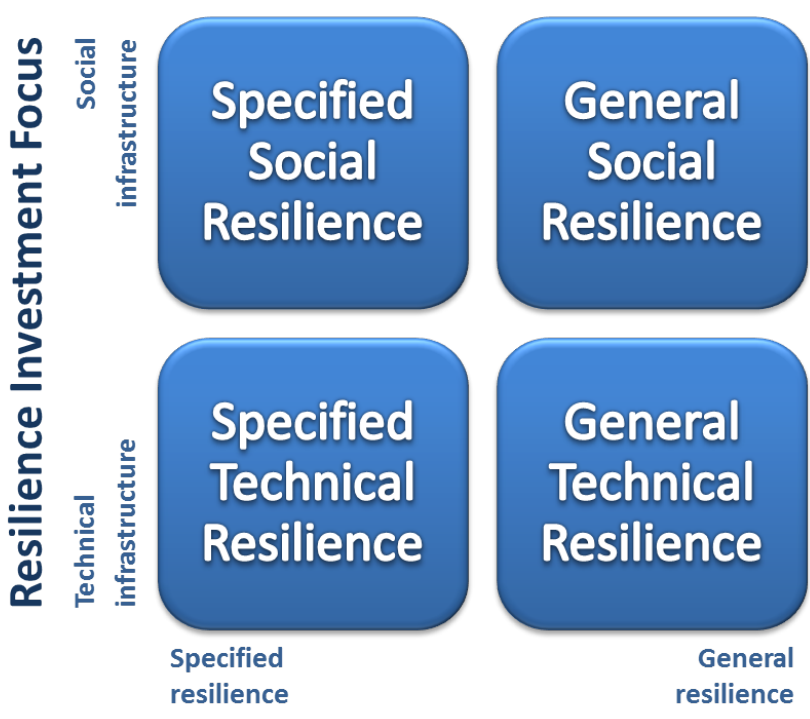

Type of Resilience

\section{Differentiated resilience roles}

These different forms of resilience can be cultivated at different organizational levels (operational, tactical, and strategic). The organization has been conceptualized as a layered triangle, with the operations layer being the largest bottom stratum, the tactical layer representing the middle level, and the top strategic layer representing the executive level (Anthony 1988, Mumford et al. 
Table 4. Differentiated resilience roles at different organizational levels.

\begin{tabular}{lll}
\hline \hline Operational level & Tactical level & Strategic level \\
\hline Leadership fosters persistence through & Leadership establishes integrated response & Leadership takes a long-term perspective to \\
operational control in daily operations to & capabilities, adaptability through management & transform the organization in a timely manner \\
ensure that the system has the day-to-day & control, continuous improvement, and scenario- & through emergent strategic planning to survive and \\
ability to absorb a magnitude of & based exercises to enable the organization to & thrive amid uncertainty while navigating disruptive \\
disturbances and to anchor essential & adaptively manage risk, to bounce back better, & change, to intentionally transform its identity toward \\
services with minimum disruption & and to embrace opportunities to bounce forward & a more sustainable development trajectory \\
\hline
\end{tabular}

2007, Ho 2015). The different interrelated aspects of resilience (persistence, adaptability, and transformability) can occur at multiple hierarchical levels in organizations and interact across temporal, spatial, and hierarchical scales. To foster resilient essential services, we argue that the primary role of operational leadership is to foster persistence of core operational functions, the role of tactical leadership is to develop adaptability, and the role of strategic leadership is to transform the organization in a timely manner to survive and thrive amid disruptive change (Fig. 2, Table 4). We also argue that specified resilience is crucial in the lower strata of organizations while the significance of general resilience increases higher up. Operational leaders need to be aware of external threats and mindful of internal vulnerabilities to persist. In contrast, strategic leaders need to be aware of external opportunities and mindful of internal well-being of employees to transform proactively.

Fig. 2. Resilience roles and responsibilities at different organizational levels.

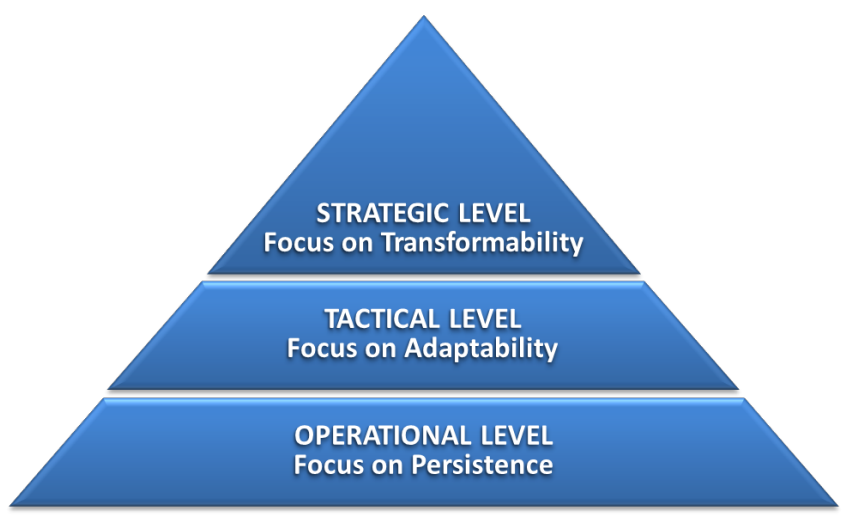

\section{APPLYING THE FRAMEWORK TO BUILD AND ASSESS RESILIENCE OF ELECTRICITY SUPPLY}

The framework introduced above can be used to identify different strategies and interventions to build the resilience of essential services in different parts of socio-technical supply systems. Applying the framework at different organizational levels can facilitate contextually appropriate assessments that help develop a deeper and shared understanding of the complex adaptive dynamics of a system in relation to the larger context in which it is embedded, a key objective of many resilience assessments (Quinlan et al. 2015). To achieve this objective, we argue that the assessment process should incorporate key resilience-building principles of facilitating broad participation, encouraging learning, and facilitating a deeper understanding of complex dynamics in the socio-technical system, while building trust and social capital (Biggs et al. 2015).

In the following sections, we discuss how the framework can be applied specifically in the context of socio-technical electricity supply systems to build and assess resilience. The four resilience quadrants can be used as a guideline for the differentiated assessment of respective types of resilience at different organizational levels. We also suggest indicators of quadrantspecific resilience applicable to specific organizational levels (Table 5).

\section{Specified technical resilience}

Specified technical resilience represents areas where investments can be made in identified infrastructure and assets to ensure that they can withstand specified threats, in answer to "resilience of what and to what?" (Carpenter et al. 2001, Quinlan et al. 2015:3). Although the timing and severity of these specified threats may be unknown, their potential future occurrence can be calculated probabilistically (O'Connell et al. 2015a). This quadrant draws on what Holling (1996) described as engineering resilience, or what is known in the electric utility world as utility resilience, reliability standards, electric power infrastructure resilience, or grid resilience (Madni and Jackson 2009, NIAC 2009, Park et al. 2013, DOE 2014, NERC 2015). The specified technical resilience domain represents level 1 technology solutions that enhance survivability and robustness (Pavard et al. 2006, Madni and Jackson 2009, Dahlberg 2015), following the laws of physics and using reductionist approaches.

\section{Building specified technical resilience}

Given adequate resources, infrastructure resilience can be achieved to withstand anticipated hazards through good practice, which includes intelligent engineering design that implements adequate margins of safety, quality construction, and sufficient maintenance (UNESCAP 2013). In a utility such as Eskom, this translates into applying engineering standards (for example, reliability criteria, quality controls, and routine inspections). Consideration should be given to fail-to-safe design philosophies (i.e., revert to a safe condition if it fails). Specified technical resilience can also be enhanced through a wider distribution of resources to increase redundancy. An example of increasing diversity and redundancy in electricity supply is the use of microgrids around critical facilities or the placement of critical spares such as spare towers or mobile transformers at select locations throughout the grid to speed up emergency response.

Assessing specified technical resilience

Specified technical resilience assessments can consist of quantitative measures (Quinlan et al. 2015), benchmarks, tests, and compliance with engineering standards and controls applied 
Table 5. Suggested quadrant-specific indicators of resilience at different organizational levels.

\begin{tabular}{|c|c|c|c|}
\hline Type of resilience & $\begin{array}{l}\text { Indicators of persistence at } \\
\text { operations level }\end{array}$ & Indicators of adaptability at tactical level & $\begin{array}{l}\text { Indicators of transformability at strategic } \\
\text { level }\end{array}$ \\
\hline $\begin{array}{l}\text { Specified technical } \\
\text { resilience }\end{array}$ & $\begin{array}{l}\text { - Infrastructure and assets well } \\
\text { managed to required standards, } \\
\text { including regular maintenance } \\
\text { and tests of back-up } \\
\text { technologies (UN ESCAP 2013) } \\
\text { - Deploy standardized } \\
\text { redundancy criteria, have } \\
\text { redundant equipment available, } \\
\text { and have efficient access to } \\
\text { operational spares to restore } \\
\text { network disruptions }\end{array}$ & $\begin{array}{l}\text { - Technical standards are adaptively revised to } \\
\text { incorporate learning; adaptive assessment } \\
\text { approaches are applied, and a portfolio of } \\
\text { technical investments exists for disaster risk } \\
\text { reduction (NDMC 2005) } \\
\text { - Strategic spares are available for contingencies } \\
\text { and response (NIAC 2010) } \\
\text { - Engineers consider build-back-better and fail- } \\
\text { to-safe design philosophies (Park et al. 2013, } \\
\text { UNISDR 2015) }\end{array}$ & $\begin{array}{l}\text { - Strategic commitment to invest in } \\
\text { resilience, reserve margins, and self-healing } \\
\text { capabilities (DOE 2014) } \\
\text { - Decision making considers effects of } \\
\text { decisions on resilience of critical processes } \\
\text { (BSI 2014) } \\
\text { - Adopt a modular substation design } \\
\text { strategy; although initial cost is higher, it can } \\
\text { allow standardization on spares and speeds } \\
\text { up recovery (Zolli and Healy 2012, Friedrich } \\
\text { et al. 2015, EPRI 2016) }\end{array}$ \\
\hline $\begin{array}{l}\text { Specified social } \\
\text { resilience }\end{array}$ & $\begin{array}{l}\text { - Competent in decisions that } \\
\text { require attention to detail and } \\
\text { precision across multiple } \\
\text { recurring iterations } \\
\text { - Competent in execution of } \\
\text { standard operating procedures, } \\
\text { emergency roles and } \\
\text { responsibilities, ability to execute } \\
\text { preapproved response plans, and } \\
\text { ability to participate effectively } \\
\text { in simulation exercises (Wybo } \\
\text { 2008) }\end{array}$ & $\begin{array}{l}\text { - Competent in semistructured decisions and } \\
\text { ensuring efficient and effective use of resources } \\
\text { through business planning, logistics } \\
\text { coordination, and operational improvements } \\
\text { - Contingency arrangements, response plans, } \\
\text { and risk reduction strategies are systematically } \\
\text { reviewed and adaptively revised to incorporate } \\
\text { learning (Saurin et al. 2013) } \\
\text { - Response structures effectively integrate across } \\
\text { functions }\end{array}$ & $\begin{array}{l}\text { Competent in unstructured decisions that } \\
\text { are complex, ambiguous, and far-reaching in } \\
\text { scope, entail high levels of uncertainty, and } \\
\text { often pertain to nonlinear risks in the } \\
\text { external environment } \\
\text { - Commitment to resilience through visible } \\
\text { leadership in good-practice disciplines such } \\
\text { as emergency preparedness and business } \\
\text { continuity management } \\
\text { - Ownership of contingency arrangements, } \\
\text { knowing and testing established plans, and } \\
\text { actively participating in emergency } \\
\text { simulation exercises } \\
\text { - Ability to anticipate and avoid } \\
\text { "foreseeable, predictable, avoidable } \\
\text { surprises"* }\end{array}$ \\
\hline $\begin{array}{l}\text { General technical } \\
\text { resilience }\end{array}$ & $\begin{array}{l}\text { - Able to operate adaptive } \\
\text { technology under pressure and } \\
\text { maintain back-up and } \\
\text { contingent systems components } \\
\text { - Technical capabilities that allow } \\
\text { operational flexibility often } \\
\text { beyond the infrastructure itself, } \\
\text { e.g., demand response contracts }\end{array}$ & $\begin{array}{l}\text { - Review asset condition monitoring practices } \\
\text { and test results of deployed technologies that } \\
\text { provide adaptive capacity and strengthen } \\
\text { systems flexibility, e.g., unit islanding schemes } \\
\text { and black-start tests performed } \\
\text { - Consider technology solutions beyond the } \\
\text { infrastructure system }\end{array}$ & $\begin{array}{l}\text { - Proactive investment in systems flexibility } \\
\text { (in electricity supply, these include smart } \\
\text { metering, smart grid, containerized mobile } \\
\text { substations, demand-side products, and } \\
\text { supply-side mix) }\end{array}$ \\
\hline $\begin{array}{l}\text { General social } \\
\text { resilience }\end{array}$ & $\begin{array}{l}\text { - Monitor whether people feel } \\
\text { empowered to act in the interest } \\
\text { of safety and resilience if } \\
\text { contrary to what is expected } \\
\text { - Able to follow intuition based } \\
\text { on deep experience in situations } \\
\text { that necessitate that rules be } \\
\text { broken } \\
\text { - During extreme events, be } \\
\text { comfortable to apply an incident } \\
\text { command system to perform } \\
\text { emergency operations, even } \\
\text { under great pressure } \\
\text { - Employ fail-to-safe scenarios in } \\
\text { emergency exercises that stretch } \\
\text { people beyond the plan }\end{array}$ & $\begin{array}{l}\text { - Able to network and mobilize support through } \\
\text { strong social networks, third-party agreements, } \\
\text { and memorandums of understanding that have } \\
\text { been established } \\
\text { - Monitor for signs of restorative or retributive } \\
\text { justice exercised in supervision } \\
\text { - Identify heuristics used on the frontline, verify } \\
\text { the validity to formalize and spread guiding } \\
\text { heuristics to be used in crises } \\
\text { - During extreme events, be comfortable to } \\
\text { coordinate planning, be able to integrate } \\
\text { situational awareness during the incident to } \\
\text { provide a common operational picture of } \\
\text { unfolding events, execute tactical command, } \\
\text { mobilize resources, and coordinate logistics to } \\
\text { support operations }\end{array}$ & $\begin{array}{l}\text { - Actively build a culture of resilience and } \\
\text { safety, with restorative justice in word and } \\
\text { deed; the ability to anticipate and avoid } \\
\text { predictable surprises } \\
\text { - Evidence that they value and actively build } \\
\text { social and psychological capital in their } \\
\text { networks and through their leadership, } \\
\text { practice adaptive management, and } \\
\text { encourage decentralized self-organization } \\
\text { during disruption (Jones } 2011 \text {, Pereira and } \\
\text { Ruysenaar } 2012 \text {, Everly et al. 2013) } \\
\text { - Strengthen external and internal } \\
\text { connections in functions, across disciplines, } \\
\text { and with other sectors (Stephenson } 2010 \text { ) } \\
\text { - During extreme events, be comfortable to } \\
\text { fulfill the incident commander role, be able } \\
\text { to see the big picture, prioritize objectives, } \\
\text { take decisions in spite of incomplete } \\
\text { information, and recognize when a phase } \\
\text { change is evident or a regime shift has taken } \\
\text { place }\end{array}$ \\
\hline
\end{tabular}

See Anthony (1988), Mumford et al. (2007), Ho (2015).

${ }^{\dagger}$ See Bazerman and Watkins (2008). 
throughout the asset life cycle. Reliability assessments contribute toward technical resilience, but reliability is not enough to ensure resilience to low-probability high-consequence events (Stockton 2014, Panteli and Mancarella 2015). Because of an increase in severe weather events due to climate change, the resilience of technologies already deployed should be monitored (Savonis et al. 2014) to harden or reinforce existing infrastructure and modernize aging infrastructure to withstand severe climate events (Panteli and Mancarella 2015), and reliability design criteria for infrastructure should be revised to cater for new extremes.

When infrastructure is damaged in disasters (for example, due to severe weather), the global Sendai Framework for Disaster Risk Reduction suggests that asset owners consider the option to build back better (UNISDR 2015) to enable "bouncing forward" (Kelman et al. 2015:22). In addition, adaptive assessment approaches can be employed to verify the reliability and resilience of current infrastructure in relation to the increased probability and intensity of severe weather events. A risk assessment of climate-resilient infrastructure can identify assets vulnerable to inundation or structural failure to inform an infrastructure resilience investment strategy for disaster risk reduction (NDMC 2005). Within Eskom, the systematic application of this approach is prescribed in the disaster management strategy in the form of disaster risk assessments and disaster risk reduction. This process demonstrates the cyclical nature of assessing resilience to build resilience.

\section{Specified social resilience}

Specified social resilience entails specific investments in people and processes to ensure that they can maintain the continuity of critical functions when subjected to identified threats. This quadrant draws on the management disciplines of emergency management, crisis management, business continuity management, and safety management, as well as literature from the fields of organizational resilience, climate resilience, and disaster management (Linnenluecke and Griffiths 2012, Miao et al. 2013, Mendonça and Wallace 2015). The adequacy of people's technical skills draws on the traditional reductionist approaches of sociotechnical systems thinking and human-machine interface design (Dekker 2005, Qureshi 2007, Klein 2008). To ensure safety in highrisk operations, the literature on high-reliability organizations highlights cultivating resilience mindsets (Weick et al. 1999, Schulman et al. 2004, Lekka 2011).

\section{Building specified social resilience}

Specified social resilience can be built through the adoption of established disciplines of good practice (BSI 2014). The Eskom Resilience Programme is based on the adoption of emergency management, business continuity management, and disaster management at different scales across the organization, using risk management as a common basis, and incident management integrated at the time of response across functional and geographic boundaries (Koch et al. 2013). Through the adoption of these management systems, response preparedness and contingency arrangements are formally established. While these good-practice guidelines are aimed at specific response capabilities, the process can also contribute to general social resilience when people synthesize the wider context and recognize the purpose of these processes.
To develop the cognitive ability to deal with the disruption of extreme events, an effective response capability can be developed, but there is no substitute for experience (Cilliers 2000, Casto 2014, Doyle et al. 2015). Operators need the ability to recognize system failure conditions and arrest the collapse of technical infrastructure systems. Because real resilience tests seldom occur, this experience can be built up through being exposed to stretching scenarios in simulation exercises (Wybo 2008, Koch et al. 2013, Kellett and Peters 2014). The apprentice program for a new system operator to autonomously man a desk in Eskom National Control lasts longer than a decade and includes extensive time on the simulator. Participation in emergency exercises and simulations is vital to build and assess resilience (Wybo 2008).

Continuous learning is a vital resilience-enhancing principle (Biggs et al. 2012). While incident investigations assess root causes, they also propose preventive measures. Collectively, these findings can be useful in facilitating adaptation requirements that build specified resilience. Highly reliable organizations cultivate collective mindfulness that pays attention to small signals, for example, when incidents result in responses at a systemic level that are outside of the expected norms (Weick et al. 1999). Such organizations learn from their and others' mistakes to "fail forward." At a wider scale, specified social resilience can be enhanced by changing the rules of the game such as by redesigning the regulatory framework to support resilience (NIAC 2010, Keogh and Cody 2013), increasing the range of options (e.g., having critical load specifications for the utility or diversifying the energy options for customers), and increasing the size of buffers through energy demand management programs.

\section{Assessing specified social resilience}

Specified social resilience assessments can entail a verification of established preparedness against predefined objectives in the form of authorized contingency arrangements, response and recovery plans, and standard operating procedures. Such assessments can be done based on the guidelines of good-practice disciplines such as emergency preparedness, business continuity management, and disaster management. Various indicators of specified social capabilities have been recommended to enable repeatable and comparable resilience assessments (McManus et al. 2007, Stephenson 2010, Lee et al. 2013, Matzenberger et al. 2015). Within Eskom, divisional and provincial progress is monitored against key deliverables as part of an enterprise resilience program. The role of exercises in specified social resilience assessments is to test execution against these predefined plans and to verify the effectiveness of the preparedness at a disaggregated level in organizations. Such integrated provincial and national exercises are conducted annually in Eskom.

\section{General technical resilience}

General technical resilience refers to the generic ability of manmade systems to withstand any threat or disruption amid the complexity of the level 2 systems in which they are embedded. This quadrant draws on network topology, resilience engineering, systems resilience, systems of systems, and critical infrastructure systems literature (Hollnagel et al. 2006, Janssen et al. 2006, Dekker et al. 2008, McDaniels et al. 2008, Gopalakrishnan and Peeta 2010, Stockton 2014, Amin 2015, Gao et al. 2016). The field of resilience engineering should be distinguished from 
engineering resilience described by Holling (1996). Resilience engineering applies a complexity perspective to the safety of manmade systems by ensuring that the overall socio-technical system has the capacity to withstand a threat, the flexibility to restructure itself in the face of a threat, the tolerance to degrade gracefully following an encounter with a threat, and the cohesion to operate before, during, and after an encounter with a threat (Dekker et al. 2008, Jackson 2008).

\section{Building general technical resilience}

Building general technical resilience requires increasing systemslevel flexibility that allows bending rather than breaking (Longstaff et al. 2014, Dahlberg 2015). It entails optimizing network topology for resilience to maintain connectivity amid disruption, although there can be a trade-off with network efficiency (Gutfraind 2012, Gao et al. 2016). General technical resilience can be strengthened through technology that enables emergent and adaptive approaches that support novel self-service capabilities through, for example, built-in fail-to-safe modes and just-in-case contingency capacities that accommodate systems failure and manage failure and recovery (Park et al. 2013, Seville et al. 2015). Measures that increase system adaptation under system failure conditions include systems-level flexibility, increased observability and controllability, permeable systems boundaries that are less brittle under pressure (Rumbaitis del Rio 2015), and tools that support rapid response and recovery (Schneider and Somers 2006, Francis and Bekera 2014, Panteli and Mancarella 2015). By extrapolating from resilience in socialecological systems, general technical resilience can be enhanced by paying attention to energy flows, systems-level feedback loops, slow variables, thresholds, and interdependencies in the system.

In the electricity industry, general technical resilience is a key consideration in the focus on smart grid technology. For example, smart metering enables connectivity with improved information flow, controllability, and dynamic reconfigurability of the system; self-healing networks enable technical systems to self-organize following disruption; and microgrids enable modularity, diversity, and redundancy (Lacey 2014, Ye 2014, Zarakas et al. 2014). Regulatory requirements that enable the flexible management of real-time electricity demand reduction in the event of a range of scenarios in South Africa include the establishment of critical and essential load requirements as well as interruptible load contracts (SABS 2010). General technical resilience can also be built into communities, for example, by diversifying energy options such as solar-powered traffic lights to prevent gridlock when power supply fails and through the use of peak-day pricing, stimulating energy efficiency that improves peak demand reduction and contributes to overall systems efficiency.

\section{Assessing general technical resilience}

Assessments of general technical resilience need to appraise levels of general technical resilience of the critical infrastructure system through an evaluation of the flexibility of the overall system when under strain or under failure conditions that may not yet be apparent. Metrics are available for the resilience of complex networks based on network topology and system dynamics (Zhao et al. 2011, Gao et al. 2016). Indicators of general technical resilience identified for socio-technical systems include safety margins, buffers and levels of redundancy built into the design and operations of the system (Madni and Jackson 2009). Potential indicators, inferred from social-ecological systems, include systems-level connectivity and barriers (Biggs et al. 2015). Drawing on Cork's (2011) work on resilient ecosystems, general resilience indicators applicable to assessment of technical systems include: modularity in the connections of components in the network to ensure that the overall system continues to function even if one part of the system has collapsed (referred to as redundancy and diversity by Woods [2005]); tight feedback mechanisms through which information about change is gathered and transmitted through the system (referred to as observability by Savulescu [2014]) to ensure adequate, timely, and scaleappropriate response (referred to as controllability by Panteli and Mancarella [2015]), and; levels of just-in-case economic and system reserves that can be drawn from if something untoward happens (Seville et al. 2015).

The cost of general technical resilience investments is high, and there is no certainty about when it is enough. We therefore propose balancing investments in this quadrant with resilience investments in general social resilience because the uniquely human strength to adjust and improvise enhances the adaptability of complex level 2 socio-technical systems (Dekker 2005, Heese et al. 2014).

\section{General social resilience}

General social resilience refers to investments in people and processes to ensure that the overall socio-technical system has continuity and a general ability to cope with dynamic change in the face of novel and unanticipated disruptions. This quadrant focuses on learning to adapt to change, preparing the system for emergent self-organization, and using complexity leadership thinking to renew the system should large shocks occur (Comfort et al. 2001, Marion and Uhl-Bien 2001, Walker et al. 2002, Kaufmann 2013). This quadrant draws on psychology, behavioral and social sciences, community resilience literature (DuPlessis VanBreda 2001, Youssef and Luthans 2007, Armitage et al. 2012, Carpenter et al.2012), the fields of ergonomics and human factors (Qureshi 2007, Klein 2008, Dekker 2012, NIST 2016b), as well as the side of resilience engineering that helps people who operate within complex socio-technical systems to cope with complexity under pressure and endure (Hollnagel et al. 2006, Righi et al. 2015).

\section{Building general social resilience}

Eskom has identified five generic social capabilities of a resilient essential service system, namely: (1) anticipate, identify, and adapt rapidly to threats, vulnerabilities, and opportunities arising from changes in the internal and external environment; (2) operate at elevated levels of stress without failure for extended periods of time; (3) respond rapidly to a shock to contain the impact (severity and duration) of the event or threat; (4) recover rapidly in a coordinated manner; and (5) deliberately evolve to a higher state of resilience in response to changes in the environment by implementing learning from near misses and incidents (Koch et al. 2013). These general social resilience capabilities can be nurtured through investment in social, cultural, and educational competencies (PwC 2013).

An organizational culture of resilience can be fostered through behaviors that help employees to be agile and adaptive in the face of disruption and change (Luthans et al. 2006, Everly et al. 2013). Organizations can encourage purposive self-organization (Pavard et al. 2006, Shaw et al. 2014, De Coning 2016). For instance, a 
standard incident command system offers a flexible and highly adaptive management system that enables dynamic selforganization, yet ensures coordination toward common incident objectives (Maitlis and Christianson 2014). Empowering leadership that explicitly gives people permission to act in a hightrust environment (Jones 2011) makes space for personal commitment that unlocks determination and willpower (Conway et al. 1974) and can contribute significantly to resilient organizational response to disruption (Nguyen et al. 2016).

\section{Assessing general social resilience}

Sense of coherence has arisen as a significant indicator of individual and societal resilience (DuPlessis VanBreda 2001, Almedom et al. 2007, Overland 2011). It refers to how people make sense of everyday reality and whether they view life and the world as comprehensible, manageable, and meaningful (Lindström and Eriksson 2006, Almedom et al. 2007). A healthy sense of coherence provides the ability to cope with stressful situations (Eriksson and Lindström 2005); contributes to preventive, protective, and restorative capacity in people subjected to disruption; and influences survival and recovery (DuPlessis VanBreda 2001, Overland 2011). Furthermore, cultivating a restorative safety culture that is just (rather than retributive) significantly contributes to resilience because it enables an organization to learn from mistakes rather than focusing on attributing blame, which can result in covering up incidents or tampering with evidence (Dekker and Breakey 2016). Effective learning processes can be facilitated through adaptive management (Hummelbrunner and Jones 2013b) and adaptive governance systems (Folke et al. 2005, Garschagen 2013, Seeliger and Turok 2014).

The general social resilience quadrant represents a highly soughtafter resilience advantage but is the most difficult to establish or assess. Assessments of general social resilience require sense making that engages with contextual complexity. General resilience assessment indicators adapted from Cork (2011) include monitoring for change in: (1) levels of openness in the system for the movement of people and ideas into, through, and out of the system; (2) levels of social reserves, and; (3) levels of social and relational capital such as leadership, networks, community, and trust exhibited in the system (Pereira and Ruysenaar 2012). General social resilience can also potentially be assessed by measuring and monitoring collective sense of coherence (Ghoshal and Bruch 2003, Lindström and Eriksson 2006); evaluating the presence and effectiveness of the seven generic principles proposed by Biggs et al. (2015), and; evaluating the nature of the culture, informal institutions, and heuristics used to make judgements under uncertainty (Tversky and Kahneman 1974, North 1991, Pereira and Ruysenaar 2012).

\section{CONCLUSION}

The resilience of technologically mediated essential services is critical to human well-being. These essential services are produced by complex adaptive socio-technical systems that consist of layers of critical infrastructure embedded within people and processes in organizations responsible for delivering these services. Here, we make a novel contribution by conceptualizing the resilience of essential services in terms of both specified parts and the whole of the complex adaptive socio-technical system that produces essential services. The framework we propose juxtaposes and distinguishes between specified and general resilience investments in (1) people and institutions as a social infrastructure investment, and (2) infrastructure and assets as a technology infrastructure investment (Fig. 1). This four-quadrant framework provides a guide to a differentiated but integrated set of resilience strategies and assessment indicators that can be applied across different organizational levels.

We suggest that all four quadrants of the proposed framework should be applied at all organizational levels. However, the relative importance of specified and general resilience varies across these levels: specified resilience is more pertinent at the operational level, whereas general resilience is more pertinent at the strategic level (Fig. 2). This difference partly explains why reductionist approaches have been dominant in considering resilience of infrastructure systems because the emphasis is on continuity of technical operations amid disruption. However, as the concept of resilience thinking matures in essential service provision, we expect that complex adaptive systems thinking will increasingly permeate resilience practice. All four dimensions of resilience are important, but general social resilience in essential service systems in particular has generally been neglected.

Specified resilience can be built in a linear fashion based on good practice, but general resilience needs to be built in an emergent fashion, drawing on approaches from complex adaptive systems thinking. Technological resilience investments generally reduce vulnerability and mitigate failure, whereas social resilience investments increase available options and enhance collective adaptability. Both forms of resilience are necessary to safeguard essential services against systems failure. Both reductionist and complexity-based approaches to resilience add value and should be employed in a complementary, rather than competitive or exclusive, fashion. When either approach is used exclusively, it might erode resilience.

We argue that formative resilience assessments can be conducted for building resilience of essential services based on social and technical indicators of specified and general resilience. To stimulate the emergence of social resilience across the system, a key aspect of formative resilience assessments is identifying and conducting critical conversations at different organizational levels. By stimulating appropriate discussions at multiple levels, resilience assessments can promote adaptation and transformation of the system and stimulate the emergence of resilience across the system.

More work is required to understand the options to assess and build resilience of socio-technical systems and, in particular, the social dynamics required to ensure resilient essential service delivery. Humans can be both the weakest link and the strongest resource to ensure resilience of essential services. More research is required on how to build a culture of resilience in key service providers and to develop and understand techniques that foster social resilience. Although we have focused on the case of sociotechnical systems, we suggest that the approach we have adopted in our framework may be useful for advancing thinking and indicator development in social-ecological systems more broadly, for instance, by overlaying specified and general resilience against societies and ecosystems. We suggest that this approach can support the operationalization of resilience assessments that can identify and integrate a diverse portfolio of resilience-enhancing initiatives and investment strategies. 
Responses to this article can be read online at: http://www.ecologyandsociety.org/issues/responses. php/9623

\begin{abstract}
Acknowledgments:
We are grateful to Robert Koch who read and commented on several versions of the paper, and to two anonymous reviewers whose inputs were valuable in clarifying and strengthening the paper. The authors are supported by the South African Research Chairs Initiative of the Department of Science and Technology and National Research Foundation of South Africa (grant 98766), the Guidance for Resilience in the Anthropocene: Investments for Development (GRAID) project funded by the Swedish International Development Agency (SIDA), and a Young Researcher grant (621-2014-5137) funded by Vetenskaprådet in Sweden.
\end{abstract}

\section{LITERATURE CITED}

Abi-Samra, N., J. McConnach, S. Mukhopadhyay, and B. Wojszczyk. 2014. When the bough breaks, managing extreme weather events affecting electrical power grids. IEEE Power and Energy Magazine 12(5):61-65. http://dx.doi.org/10.1109/ MPE.2014.2331899

Aldunce, P., R. Beilin, M. Howden, and J. Handmer. 2015. Resilience for disaster risk management in a changing climate: practitioners' frames and practices. Global Environmental Change 30:1-11. http://dx.doi.org/10.1016/j.gloenvcha.2014.10.010

Allan, P., and M. Bryant. 2014. The attributes of resilience: a tool in the evaluation and design of earthquake-prone cities. International Journal of Disaster Resilience in the Built Environment 5(2):109-129. https://doi.org/10.1108/IJDRBE-05-2012-0013

Allenby, B. R., and D. Sarewitz. 2011. The techno-human condition. MIT Press, Cambridge, Massachusetts, USA.

Almedom, A. M., B. Tesfamichael, Z. S. Mohammed, C. G. N. Mascie-Taylor, and Z. Alemu. 2007. Use of 'sense of coherence (SOC)' scale to measure resilience in Eritrea: interrogating both the data and the scale. Journal of Biosocial Science 39(1):91-107. http://dx.doi.org/10.1017/S0021932005001112

Amin, M. 2015. System-of-systems approach. Pages 317-354 in E. Kyriakides and M. Polycarpou, editors. Intelligent monitoring, control, and security of critical infrastructure systems. Springer, Berlin, Germany. http://dx.doi.org/10.1007/978-3-662-44160-2 12

Ancona, D. 2012. Sensemaking: framing and acting in the unknown. Pages 3-19 in S. Snook, N. Nohria, and R. Khurana, editors. The handbook for teaching leadership: knowing, doing, and being. Sage, Los Angeles, California, USA.

Anthony, R. N. 1988. The management control function. Harvard Business School Press, Boston, Massachusetts, USA.

Armitage, D., C. Béné, A. T. Charles, D. Johnson, and E. H. Allison. 2012. The interplay of well-being and resilience in applying a social-ecological perspective. Ecology and Society 17 (4):15. http://dx.doi.org/10.5751/ES-04940-170415
Auerswald, P. E., L. M. Branscomb, T. M. La Porte, and E. O. Michel-Kerjan, editors. 2006. Seeds of disaster, roots of response: how private action can reduce public vulnerability. Cambridge University Press, New York, New York, USA. http://dx.doi. org/10.1017/CBO9780511509735

Barnett, B. 2016. An evaluation of the UK's use of SFM standards to procure solid woody biomass for electricity generation using sustainable bioenergy criteria. Biofuels 7(1):1-11. http://dx.doi. org/10.1080/17597269.2015.1118775

Barrett, C. B., and M. A. Constas. 2014. Toward a theory of resilience for international development applications. Proceedings of the National Academy of Sciences 111(40):14625-14630. https:// doi.org/10.1073/pnas.1320880111

Bazerman, M. H., and M. D. Watkins. 2008. Predictable surprises: the disasters you should have seen coming, and how to prevent them. Harvard Business Review Press, Boston, Massachusetts, USA.

Berkes, F. 2007. Understanding uncertainty and reducing vulnerability: lessons from resilience thinking. Natural Hazards 41(2):283-295. http://dx.doi.org/10.1007/s11069-006-9036-7

Bhamra, R., S. Dani, and K. Burnard. 2011. Resilience: the concept, a literature review and future directions. International Journal of Production Research 49(18):5375-5393. https://doi. org $/ 10.1080 / 00207543.2011 .563826$

Biggs, R., M. Schlüter, D. Biggs, E. L. Bohensky, S. BurnSilver, G. Cundill, V. Dakos, T. M. Daw, L. S. Evans, K. Kotschy, A. M. Leitch, C. Meek, A. Quinlan, C. Raudsepp-Hearne, M. D. Robards, M. L. Schoon, L. Schultz, and P. C. West. 2012. Toward principles for enhancing the resilience of ecosystem services. Annual Review of Environment and Resources 37:421-448. http:// dx.doi.org/10.1146/annurev-environ-051211-123836

Biggs, R., M. Schlüter, and M. L. Schoon, editors. 2015. Principles for building resilience: sustaining ecosystem services in socialecological systems. Cambridge University Press, Cambridge, UK.

Black, P., and D. Wiliam. 2009. Developing the theory of formative assessment. Educational Assessment, Evaluation and Accountability 21:5-31. https://doi.org/10.1007/s11092-008-9068-5

Bo, Z., O. Shaojie, Z. Jianhua, S. Hui, W. Geng, and Z. Ming. 2015. An analysis of previous blackouts in the world: lessons for China's power industry. Renewable and Sustainable Energy Reviews 42:1151-1163. http://dx.doi.org/10.1016/j.rser.2014.10.069

Bocca, R., and E. Mehlum. 2012. New energy architecture: enabling an effective transition. World Economic Forum, Geneva, Switzerland. [online] URL: http://reports.weforum.org/newenergy-architecture-enabling-an-effective-transition-2012/\#

Bohensky, E. L., L. S. Evans, J. M. Anderies, D. Biggs, and C. Fabricius. 2015. Principle 4 - foster complex adaptive systems thinking. Pages 142-173 in R. Biggs, M. Schlüter, and M. L. Schoon, editors. Principles for building resilience: sustaining ecosystem services in social-ecological systems. Cambridge University Press, Cambridge, UK.

Boin, A., and M. J. G. van Eeten. 2013. The resilient organization. Public Management Review 15(3):429-445. https://doi. org/10.1080/14719037.2013.769856 
British Standards Institution (BSI). 2014. BS 65000:2014: guidance on organizational resilience. British Standards Institution, London, UK.

Cabinet Office. 2011. Strategic national framework on community resilience. Cabinet Office, London, UK. [online] URL: https:// www.oxfordshire.gov.uk/cms/sites/default/files/folders/documents/ fireandpublicsafety/emergency/StrategicNationalFramework.pdf

Cabinet Office. 2015. National risk register of civil emergencies: 2015 edition. Cabinet Office, London, UK. [online] URL: https:// www.gov.uk/government/uploads/system/uploads/attachment data/ file/419549/20150331_2015-NRR-WA_Final.pdf

Caldwell, B. S. 2014. Cognitive challenges to resilience dynamics in managing large-scale event response. Journal of Cognitive Engineering and Decision Making 8(4):318-329. http://dx.doi. org/10.1177/1555343414546220

Carpenter, S., B. Walker, J. M. Anderies, and N. Abel. 2001. From metaphor to measurement: Resilience of what to what? Ecosystems 4(8):765-781. https://doi.org/10.1007/s10021-001-0045-9

Carpenter, S. R., K. J. Arrow, S. Barrett, R. Biggs, W. A. Brock, A.-S. Crépin, G. Engström, C. Folke, T. P. Hughes, N. Kautsky, C.-Z. Li, G. McCarney, K. Meng, K.-G. Mäler, S. Polasky, M. Scheffer, J. Shogren, T. Sterner, J. R. Vincent, B. Walker, A. Xepapadeas, and A. de Zeeuw. 2012. General resilience to cope with extreme events. Sustainability 4(12):3248-3259. http://dx. doi.org/10.3390/su4123248

Casto, C. A. 2014. Crisis management: a qualitative study of extreme event leadership. Dissertation. Kennesaw State University, Kennesaw, Georgia, USA. [online] URL: http:// digitalcommons. kennesaw.edu/etd/626/

Chettiar, M., K. Lakmeeharan, and R. G. Koch. 2009. Review of the January 2008 electricity crisis. Eskom, Johannesburg, South Africa. [online] URL: https://www.ee.co.za/wp-content/uploads/ legacy/Energize Oct09/01 GT Review.pdf

Cilliers, P. 2000. Knowledge, complexity, and understanding. Emergence: Complexity and Organization 2(4):7-13. [online] URL: https://journal.emergentpublications.com/article/knowledgecomplexity-and-understanding/

Cilliers, P. 2007. The philosophical importance of thinking complexity. Pages 3-5 in P. Cilliers, editor. Thinking complexity. ISCE Publishing, Mansfield, Massachusetts, USA.

City of New York. 2013. Utilities. Pages 105-130 in A stronger, more resilient New York. City of New York, New York, New York, USA. [online] URL: http://www.nyc.gov/html/sirr/html/report/ report.shtml

Comfort, L. K., Y. Sungu, D. Johnson, and M. Dunn. 2001. Complex systems in crisis: anticipation and resilience in dynamic environments. Journal of Contingencies and Crisis Management 9 (3):144-158. http://dx.doi.org/10.1111/1468-5973.00164

Conway, P. W., D. C. Jordan, and D. T. Streets, editors. 1974. Development of volitional competence. MSS Information Corporation, New York, New York, USA.

Cork, S., editor. 2009. Brighter prospects: enhancing the resilience of Australia. Australia21, Weston, Australia. [online] URL: $\underline{\text { http:// }}$ australia21.org.au/wp-content/uploads/2013/08/

BARBrighterProspectsReport2.pdf

Cork, S. 2011. A framework for assessing resilience in SoE 2011 reporting. Report prepared for the Department of Sustainability, Environment, Water, Population and Communities on behalf of the State of the Environment 2011 Committee. DSEWPaC, Canberra, Australia. [online] URL: https://soe.environment.gov. au/sites/g/files/net806/f/soe2011-supplementary-framework-assessingresilience-soe-2011-reporting.pdf

Cumming, G. S., G. Barnes, S. Perz, M. Schmink, K. E. Sieving, J. Southworth, M. Binford, R. D. Holt, C. Stickler, and T. Van Holt. 2005. An exploratory framework for the empirical measurement of resilience. Ecosystems 8(8):975-987. http://dx. doi.org/10.1007/s10021-005-0129-Z

Dahlberg, R. 2015. Resilience and complexity: conjoining the discourses of two contested concepts. Culture Unbound: Journal of Current Cultural Research 7:541-557. http://dx.doi. org/10.3384/cu.2000.1525.1572541

De Coning, C. 2016. From peacebuilding to sustaining peace: implications of complexity for resilience and sustainability. Resilience 4(3):166-181. http://dx.doi.org/10.1080/21693293.2016.1153773

Dekker, S. 2012. Complexity, signal detection, and the application of ergonomics: reflections on a healthcare case study. Applied Ergonomics 43(3):468-472. http://dx.doi.org/10.1016/j.apergo.2011.07.003

Dekker, S., E. Hollnagel, D. D. Woods, and R. Cook. 2008. Resilience engineering: new directions for measuring and maintaining safety in complex systems. Lund University School of Aviation, Lund, Sweden.

Dekker, S. W. A. 2005. Ten questions about human error: a new view of human factors and system safety. Lawrence Erlbaum, Mahwah, New Jersey, USA.

Dekker, S. W. A., and H. Breakey. 2016. 'Just culture:' improving safety by achieving substantive, procedural and restorative justice. Safety Science 85:187-193. http://dx.doi.org/10.1016/j.ssci.2016.01.018

Dobson, I., B. A. Carreras, V. E. Lynch, and D. E. Newman. 2007. Complex systems analysis of series of blackouts: cascading failure, critical points, and self-organization. Chaos: an Interdisciplinary Journal of Nonlinear Science 17:026103. http:// dx.doi.org/10.1063/1.2737822

Doyle, E. E. H., D. Paton, and D. M. Johnston. 2015. Enhancing scientific response in a crisis: evidence-based approaches from New Zealand. Journal of Applied Volcanology 4:1. https://doi. org/10.1186/s13617-014-0020-8

DuPlessis VanBreda, A. 2001. Resilience theory: a literature review. South African Military Health Service, Military Psychological Institute, Social Work Research and Development, Pretoria, South Africa. [online] URL: http://vanbreda.org/ adrian/resilience/resilience theory review.pdf

Electric Power Research Institute (EPRI). 2016. Electric power system resiliency: challenges and opportunities. Electric Power Research Institute, Palo Alto, California, USA. [online] URL: https://www.naseo.org/Data/Sites/1/resiliency-white-paper.pdf 
Eriksson, M., and B. Lindström. 2005. Validity of Antonovsky's sense of coherence scale: a systematic review. Journal of Epidemiology and Community Health 59(6):460-466. http://dx. doi.org/10.1136/jech.2003.018085

Eskom. 2016a. Eskom Holdings corporate plan, financial years 2016/16-2020/21, towards surplus capacity. Eskom, Johannesburg, South Africa.

Eskom. 2016b. Eskom disaster management plan. Eskom, Johannesburg, South Africa.

Everly, G. S. Jr., K. J. Smith, and R. Lobo. 2013. Resilient leadership and the organizational culture of resilience: construct validation. International Journal of Emergency Mental Health 15 (2):123-128.

Executive Office of the President. 2013. Economic benefits of increasing electric grid resilience to weather outages. Executive Office of the President, Washington, D.C., USA. [online] URL: https://energy.gov/sites/prod/files/2013/08/f2/Grid $\% 20$ Resiliency $\%$ 20Report_FINAL.pdf

Federal Emergency Management Agency (FEMA). 2015. Effective coordination of recovery resources for state, tribal, territorial and local incidents. FEMA, Washington, D.C., USA. [online] URL: https:/www.fema.gov/media-library/assets/ documents/101940

Folke, C. 2006. Resilience: the emergence of a perspective for social-ecological systems analyses. Global Environmental Change 16(3):253-267. http://dx.doi.org/10.1016/j.gloenvcha.2006.04.002

Folke, C. 2016. Resilience. Oxford research encyclopedia: environmental science. Oxford University Press, Oxford, UK. http://dx.doi.org/10.1093/acrefore/9780199389414.013.8

Folke, C., R. Biggs, A. V. Norström, B. Reyers, and J. Rockström. 2016. Social-ecological resilience and biosphere-based sustainability science. Ecology and Society 21(3):41. http://dx.doi.org/10.5751/ ES-08748-210341

Folke, C., S. Carpenter, T. Elmqvist, L. Gunderson, C. S. Holling, and B. Walker. 2002. Resilience and sustainable development: building adaptive capacity in a world of transformations. Ambio 31(5):437-440. http://dx.doi.org/10.1579/0044-7447-31.5.437

Folke, C., S. R. Carpenter, B. Walker, M. Scheffer, T. Chapin, and J. Rockström. 2010. Resilience thinking: integrating resilience, adaptability and transformability. Ecology and Society 15(4):20. http://dx.doi.org/10.5751/ES-03610-150420

Folke, C., T. Hahn, P. Olsson, and J. Norberg. 2005. Adaptive governance of social-ecological systems. Annual Review of Environment and Resources 30:441-473. http://dx.doi.org/10.1146/ annurev.energy.30.050504.144511

Francis, R., and B. Bekera. 2014. A metric and frameworks for resilience analysis of engineered and infrastructure systems. Reliability Engineering and System Safety 121:90-103. http://dx. doi.org/10.1016/j.ress.2013.07.004

Friedrich, B., J. Boggess, C. Stiegemeier, and P. Parikh. 2015. Taking the wind out of the next superstorm: strategies for storm preparedness and quick recovery to improve grid reliability and resiliency. On-demand Webinar. PowerED Power Education
Webinar Series. ASEA Brown Boveri (ABB), Zurich, Switzerland. [online] URL: http://www.abb.com/cawp/seitp202/ b209ae0166234372c1257e6700487c99.aspx

Gao, J., B. Barzel, and A.-L. Barabási. 2016. Universal resilience patterns in complex networks. Nature 530(7590):307-312. http:// dx.doi.org/10.1038/nature16948

Garred, K. 2013. The Australian government's approach to critical infrastructure resilience. GNSS Workshop Presentation. Australian Government Attourney General's Office, Canberra, Australia. [online] URL: http://www.acser-archive.unsw.edu.au/ events/GNSS_Vulnerability/06-KrisGarred-Australian_Government$\underline{\text { s approach to Critical Infrastructure Resilence.pdf }}$

Garschagen, M. 2013. Resilience and organisational institutionalism from a cross-cultural perspective: an exploration based on urban climate change adaptation in Vietnam. Natural Hazards 67 (1):25-46. http://dx.doi.org/10.1007/s11069-011-9753-4

Ghoshal, S., and H. Bruch. 2003. Going beyond motivation to the power of volition. MITSloan Management Review Spring 2003. [online] URL: http://sloanreview.mit.edu/article/goingbeyond-motivation-to-the-power-of-volition/

Gopalakrishnan, K., and S. Peeta, editors. 2010. Sustainable and resilient critical infrastructure systems: simulation, modeling, and intelligent engineering. Springer, Berlin, Germany. https://doi. org/10.1007/978-3-642-11405-2

Grid Resiliency Task Force. 2012. Weathering the storm: report of the Grid Resiliency Task Force. Maryland Energy Administration, Baltimore, Maryland, USA. [online] URL: https://www.bateswhite.com/media/publication/13 GridResiliencyTaskForceReport.pdf

Grøtan, T. O. 2013. To rule, or not to rule is not the question (for organizing change towards resilience in an integrated world). Pages 43-48 in I. Herrera, J. M. Schraagen, J. Van der Vorm, and D. Woods, editors. 5th symposium on resilience engineering: managing trade-offs. Resilience Engineering Association, Soesterberg, The Netherlands.

Guckenheimer, J., and J. M. Ottino. 2008. Foundations for complex systems research in the physical sciences and engineering. Report from an NSF workshop in September 2008. National Science Foundation, Arlington, Virginia, USA. [online] URL: $\underline{\text { http:// }}$ www.siam.org/about/pdf/nsf_complex_systems.pdf

Gutfraind, A. 2012. Optimizing network topology for cascade resilience. Pages 37-59 in M. T. Thai and P. M. Pardalos, editors. Handbook of optimization in complex networks: communication and social networks. Springer, New York, New York, USA. http:// dx.doi.org/10.1007/978-1-4614-0857-4 2

Heese, M., W. Kallus, and C. Kolodej. 2014. Assessing behaviour towards organizational resilience in aviation. Pages 67-74 in I. Herrera, J. M. C. Schraagen, J. van der Vorm, and D. D. Woods, editors. Proceedings 5th symposium on resilience engineering: managing trade-offs. Resilience Engineering Association, Sophia Antipolis, France. [online] URL: http://publications.tno.nl/ publication/34613515/X0B0iX/herrera-2014-resilience.pdf

Ho, J. K.-K. 2015. A review of frameworks for classification of information systems, notably on the Anthony's Triangle. 
European Academic Research 3(1):604-616. [online] URL: http:// euacademic.org/UploadArticle/1562.pdf

Holling, C. S. 1996. Engineering resilience versus ecological resilience. Pages 31-44 in P. C. Schulze, editor. Engineering within ecological constraints. National Academy Press, Washington, D. C., USA.

Holling, C. S. 2001. Understanding the complexity of economic, ecological, and social systems. Ecosystems 4(5):390-405. http:// dx.doi.org/10.1007/s10021-001-0101-5

Holling, C. S., L. H. Gunderson, and D. Ludwig. 2002. In quest of a theory of adaptive change. Pages 3-24 in L. H. Gunderson and C. S. Holling, editors. Panarchy: understanding transformations in human and natural systems. Island Press, Washington, D.C., USA.

Hollnagel, E., D. D. Woods, and N. Leveson, editors. 2006. Resilience engineering: concepts and precepts. Ashgate, Aldershot, UK.

Holman, P. 2010. Engaging emergence: turning upheaval into opportunity. Berrett-Koehler, San Francisco, California, USA. [online] URL: http://peggyholman.com/papers/engaging-emergence/

Hummelbrunner, R., and H. Jones. 2013a. A guide to managing in the face of complexity. Overseas Development Institute, London, UK. [online] URL: https://www.odi.org/sites/odi.org. uk/files/odi-assets/publications-opinion-files/8662.pdf

Hummelbrunner, R., and H. Jones. 2013b. A guide for planning and strategy development in the face of complexity. Overseas Development Institute, London, UK. [online] URL: https://www. odi.org/sites/odi.org.uk/files/odi-assets/publications-opinion-files/8287. pdf

Jackson, S. 2008. Architecting resilient systems: accident avoidance and survival and recovery from disruptions. Annual INCOSE International Symposium 18:1941-2046. http://dx.doi. org/10.1002/j.2334-5837.2008.tb00916.x

Janssen, M. A., Ö. Bodin, J. M. Anderies, T. Elmqvist, H. Ernstson, R. R. J. McAllister, P. Olsson, and P. Ryan. 2006. Toward a network perspective on the resilience of socialecological systems. Ecology and Society 11(1):15. http://dx.doi. org/10.5751/ES-01462-110115

Jeschonnek, L., P. Mucke, J. Walter, and L. Kirch, editors. 2016. World risk report 2016: focus: logistics and infrastructure. Bündnis Entwicklung Hilft and UNU-EHS, Berlin, Germany. [online] URL: http://weltrisikobericht.de/wp-content/uploads/2016/08/ WorldRiskReport2016.pdf

Jones, H. 2011. Taking responsibility for complexity: how implementation can achieve results in the face of complex problems. Working Paper 330. Overseas Development Institute, London, UK. [online] URL: https://www.odi.org/sites/odi.org.uk/files/ odi-assets/publications-opinion-files/6485.pdf

Juarrero, A. 1999. Dynamics in action: intentional behavior as a complex system. MIT Press, Cambridge, Massachusetts, USA.

Kaufmann, M. 2013. Emergent self-organisation in emergencies: resilience rationales in interconnected societies. Reslience 1 (1):53-68. http://dx.doi.org/10.1080/21693293.2013.765742
Kellett, J., and K. Peters, compilers. Dare to prepare: taking risk seriously. Compendium of background resources. Overseas Development Institute, London, UK. [online] URL: https://www. odi.org/sites/odi.org.uk/files/odi-assets/publications-opinion-files/8916. pdf

Kelman, I., J. C. Gaillard, and J. Mercer. 2015. Climate change's role in disaster risk reduction's future: beyond vulnerability and resilience. International Journal of Disaster Risk Science 6 (1):21-27. http://dx.doi.org/10.1007/s13753-015-0038-5

Keogh, M., and C. Cody. 2013. Resilience in regulated utilities. National Association of Regulatory Utility Commissioners, Washington, D.C., USA. [online] URL: https://pubs.naruc.org/ pub/536F07E4-2354-D714-5153-7A80198A436D

Khoza, R. J., and M. Adam. 2006. The structure and governance of Eskom - a case study. Pages 284-307 in C. A. Mallin, editor. International corporate governance: a case study approach. Edward Elgar, Cheltenham, UK. http://dx.doi.org/10.4337/9781845429997.00023

Klein, G. 2008. Naturalistic decision making. Human Factors 50 (3):456-460. http://dx.doi.org/10.1518/001872008X288385

Koch, R. G., S. E. van der Merwe, M. A. van Harte, and A. J. Correia. 2013. Power system resilience: a conceptual framework. In CIGRE 7th Southern Africa regional conference. CIGRE, Paris, France. [online] URL: https://e-cigre.org/publication/COLL_CAP_2013colloquium-cape-town-2013-c1-c2-c5

Koester, D., and M. L. Cohen. 2012. Electric power grid indications and warning tool. MITRE Corporation, Bedford, Massachusetts, USA. [online] URL: https://www.mitre.org/sites/default/files/ pdf/12 3623.pdf

Kolko, J. 2010. Sensemaking and framing: a theoretical reflection on perspective in design synthesis. Pages 814-822 in D. Durling, R. Bousbaci, L.-L. Chen, P. Gauthier, T. Poldma, S. RoworthStokes, and E. Stolterman, editors. Conference proceedings: 2010 Design Research Society international conference. Design Research Society, Aston-on-Trent, UK. [online] URL: http:// www.drs2010.umontreal.ca/data/DRS2010web.pdf

Kurtz, C. F., and D. J. Snowden. 2003. The new dynamics of strategy: sense-making in a complex and complicated world. IBM Systems Journal 42(3):462-483. http://dx.doi.org/10.1147/ sj.423.0462

La Porte, T. M. 2006. Managing for the unexpected: reliability and organizational resilience. Pages 71-76 in P. E. Auerswald, L. M. Branscomb, T. M. La Porte, and E. O. Michel-Kerjan, editors. Seeds of disaster, roots of response: how private action can reduce public vulnerability. Cambridge University Press, New York, New York, USA. http://dx.doi.org/10.1017/CBO9780511509735.008

Lacey, S. 2014. Resiliency: how superstorm Sandy changed America's grid. Greentech Media, Boston, Massachusetts, USA. [online] URL: https://www.greentechmedia.com/articles/featured/ resiliency-how-superstorm-sandy-changed-americas-grid\#gs.B0qyqqE

Lee, A. V., J. Vargo, and E. Seville. 2013. Developing a tool to measure and compare organizations' resilience. Natural Hazards Review 14(1):29-41. http://dx.doi.org/10.1061/(ASCE) $\underline{\text { NH.1527-6996.0000075 }}$ 
Lekka, C. 2011. High reliability organisations: a review of the literature. Research Report RR899. Health and Safety Executive, Buxton, UK. [online] URL: http://www.hse.gov.uk/research/ rrpdf/rr899.pdf

Lindström, B., and M. Eriksson. 2006. Contextualizing salutogenesis and Antonovsky in public health development. Health Promotion International 21(3):238-244. http://dx.doi. org/10.1093/heapro/dal016

Linnenluecke, M. K., and A. Griffiths. 2012. Assessing organizational resilience to climate and weather extremes: complexities and methodological pathways. Climate Change 113 (3-4):933-947. http://dx.doi.org/10.1007/s10584-011-0380-6

Longstaff, P. H., T. G. Kowslowski, and W. Geoghegan. 2014. Translating resilience: a framework to enhance communication and implementation. Pages 1-10 in I. Herrera, J. M. C. Schraagen, J. van der Vorm, and D. D. Woods, editors. Proceedings 5th symposium on resilience engineering: managing trade-offs. Resilience Engineering Association, Sophia Antipolis, France. [online] URL: http://publications.tno.nl/publication/34613515/ X0B0iX/herrera-2014-resilience.pdf

Luthans, F., G. Vogelgesang, and P. Lester. 2006. Developing the psychological capital of resiliency. Human Resource Development Review 5(1):25-44. https://doi.org/10.1177/1534484305285335

Madni, A. M., and S. Jackson. 2009. Towards a conceptual framework for resilience engineering. IEEE Systems Journal 3 (2):181-191. http://dx.doi.org/10.1109/JSYST.2009.2017397

Maitlis, S., and M. Christianson. 2014. Sensemaking in organizations: taking stock and moving forward. Academy of Management Annals 8(1):57-125. https://doi.org/10.1080/19416$\underline{520.2014 .873177}$

Marion, R., and M. Uhl-Bien. 2001. Leadership in complex organizations. Leadership Quarterly 12(4):389-418. http://dx.doi. org/10.1016/S1048-9843(01)00092-3

Matzenberger, J., N. Hargreaves, D. Raha, and P. Dias. 2015. A novel approach to assess resilience of energy systems. International Journal of Disaster Resilience in the Built Environment 6(2):168-181. http://dx.doi.org/10.1108/

IJDRBE-11-2013-0044

McDaniels, T., S. Chang, D. Cole, J. Mikawoz, and H. Longstaff. 2008. Fostering resilience to extreme events within infrastructure systems: characterizing decision contexts for mitigation and adaptation. Global Environmental Change 18(2):310-318. http:// dx.doi.org/10.1016/i.gloenvcha.2008.03.001

McManus, S., E. Seville, D. Brunsdon, and J. Vargo. 2007. Resilience management: a framework for assessing and improving the resilience of organisations. Resilient Organisations Research Report 2007/01. Resilient Organisations, Christchurch, New Zealand. [online] URL: http://hdl.handle.net/10092/2810

Meadows, D. H. 2009. Thinking in systems: a primer. Earthscan, London, UK.

Mendonça, D., and W. A. Wallace. 2015. Factors underlying organizational resilience: the case of electric power restoration in New York City after 11 September 2001. Reliability Engineering and System Safety 141:83-91. [online] URL: https://doi. org/10.1016/j.ress.2015.03.017
Miao, X., D. Banister, and Y. Tang. 2013. Embedding resilience in emergency resource management to cope with natural hazards. Natural Hazards 69(3):1389-1404. http://dx.doi.org/10.1007/ s11069-013-0753-4

Mukhopadhyay, S., and M. Hastak. 2016. Public utility commissions to foster resilience investment in power grid infrastructure. Procedia - Social and Behavioral Sciences 218:5-12. http://dx.doi.org/10.1016/j.sbspro.2016.04.005

Mumford, T. V., M. A. Campion, and F. P. Morgeson. 2007. The leadership skills strataplex: leadership skill requirements across organizational levels. Leadership Quarterly 18(2):154-166. https:// doi.org/10.1016/j.leaqua.2007.01.005

National Academies of Sciences, Engineering, and Medicine (NAS). 2017. Enhancing the resilience of the nation's electricity system. National Academies Press, Washington, D.C., USA. [online] URL: https://doi.org/10.17226/24836

National Disaster Management Centre (NDMC). 2005. Introduction: a policy framework for disaster risk management in South Africa. Government Gazette 27534(654). [online] URL: http://www.ndmc.gov.za/Documents/Legislation/framework.pdf

National Infrastructure Advisory Council (NIAC). 2009. Critical infrastructure resilience: final report and recommendations. National Infrastructure Advisory Council, Washington, D.C., USA. [online] URL: https://www.dhs.gov/sites/default/files/ publications/niac-critical-infrastructure-resilience-finalreport-09-08-09-508.pdf

National Infrastructure Advisory Council (NIAC). 2010. Framework for establishing critical infrastructure resilience goals: final report and recommendations by the Council. National Infrastructure Advisory Council, Washington, D.C., USA. [online] URL: https://www.dhs.gov/sites/default/files/publications/ niac-framework-establishing-resilience-goals-final-report-10-19-10-508. pdf

National Institute of Standards and Technology (NIST). $2016 a$. Community resilience planning guide for buildings and infrastructure systems: volume I. NIST Special Publication 1190. NIST, Gaithersburg, Maryland, USA. [online] URL: http://dx. doi.org/10.6028/NIST.SP.1190v1

National Institute of Standards and Technology (NIST). $2016 \mathrm{~b}$.

Community resilience planning guide for buildings and infrastructure systems: volume II. NIST Special Publication 1190. NIST, Gaithersburg, Maryland, USA. [online] URL: http://dx. doi.org/10.6028/NIST.SP.1190v2

Nicol, D. J., and D. Macfarlane-Dick. 2006. Formative assessment and self-regulated learning: a model and seven principles of good feedback practice. Studies in Higher Education 31(2):199-218. https://doi.org/10.1080/03075070600572090

Nguyen, Q., J. R. C. Kuntz, K. Näswall, and S. Malinen. 2016. Employee resilience and leadership styles: the moderating role of proactive personality and optimism. New Zealand Journal of Psychology 45(2):13-21.

North, D. C. 1991. Institutions. Journal of Economic Perspectives 5(1):97-112. http://dx.doi.org/10.1257/jep.5.1.97 
North American Electric Reliability Corporation (NERC). 2015. State of reliability 2015. North American Electric Reliability Corporation, Atlanta, Georgia, USA. [online] URL: http://www. nerc.com/pa/RAPA/PA/Performance $\% 20$ Analysis $\% 20 \mathrm{DL} / 2015 \%$ 20State $\% 20$ of $\% 20$ Reliability.pdf

O'Connell, D., B. Walker, N. Abel, and N. Grigg. 2015a. The resilience, adaptation and transformation assessment framework: from theory to application. CSIRO, Canberra, Australia. [online] URL: http://www.stapgef.org/sites/default/files/documents/CSIROSTAP-Resilience-Adaptation-Transformation-Assessment-FrameworkReport.pdf

O’Connell, D., B. Walker, N. Abel, N. Grigg, A. Cowie, and G. Durón. 2015b. An introduction to the Resilience, Adaptation Pathways and Transformation Assessment (RAPTA) framework. United Nations Scientific and Technical Advisory Panel, Washington, D.C., USA. [online] URL: http://www.stapgef.org/ sites/default/files/stap/wp-content/uploads/2015/07/Summary_RAPTA. pdf.-July-16.pdf

Overland, G. 2011. Generating theory, biographical accounts and translation: a study of trauma and resilience. International Journal of Social Research Methodology 14(1):61-75. http://dx.doi. org/10.1080/13645579.2010.483078

Panteli, M., and P. Mancarella. 2015. The grid: stronger, bigger, smarter?: Presenting a conceptual framework of power system resilience. IEEE Power and Energy Magazine 13(3):58-66. http:// dx.doi.org/10.1109/MPE.2015.2397334

Park, J., T. P. Seager, P. S. C. Rao, M. Convertino, and I. Linkov. 2013. Integrating risk and resilience approaches to catastrophe management in engineering systems. Risk Analysis 33(3):356-367. [online] URL: http://dx.doi.org/10.1111/j.1539-6924.2012.01885. $\underline{x}$

Pasteur, K. 2011. From vulnerability to resilience: a framework for analysis and action to build community resilience. Practical Action Publishing, Rugby, UK.

Pavard, B., J. Dugdale, N. B.-B. Saoud, S. Darcy, and P. Salembier. 2006. Design of robust socio-technical systems. In 2nd symposium on resilience engineering. Resilience Engineering Association, Sophia-Antipolis, France. [online] URL: http://www.resilienceengineering-association.org/download/resources/symposium/ symposium-2006(2)/Pavard et al R.pdf

Pereira, L. M., and S. Ruysenaar. 2012. Moving from traditional government to new adaptive governance: the changing face of food security responses in South Africa. Food Security 4(1):41-58. http://dx.doi.org/10.1007/s12571-012-0164-5

Pescaroli, G., and D. Alexander. 2015. A definition of cascading disasters and cascading effects: going beyond the "toppling dominos" metaphor. Planet@Risk 3(1). [online] URL: https:// planet-risk.org/index.php/pr/article/view/208/355

Poli, R. 2013. A note on the difference between complicated and complex social systems. Cadmus 2(1):142-147. [online] URL: http://cadmusjournal.org/article/volume-2/issue-1-part-3/note-differencebetween-complicated-and-complex-social-systems

Pourbeik, P., P. S. Kundur, and C. W. Taylor. 2006. The anatomy of a power grid blackout: root causes and dynamics of recent major blackouts. IEEE Power and Energy Magazine 4(5):22-29. http://dx.doi.org/10.1109/MPAE.2006.1687814

PricewaterhouseCoopers (PwC). 2013. Rebuilding for resilience: fortifying infrastructure to withstand disaster. PricewaterhouseCoopers, London, UK.

Quinlan, A. E., M. Berbés-Blázquez, L. J. Haider, and G. D. Peterson. 2015. Measuring and assessing resilience: broadening understanding through multiple disciplinary perspectives. Journal of Applied Ecology 53(3):677-687. http://dx.doi.org/10.1111/136$\underline{5-2664.12550}$

Qureshi, Z. H. 2007. A review of accident modelling approaches for complex socio-technical systems. Pages 47-59 Proceedings of the twelfth Australian workshop on safety critical systems and software and safety-related programmable systems. Volume 86. Australian Computer Society, Canberra, Australia. [online] URL: http://crpit.com/confpapers/CRPITV86Qureshi.pdf

Ramalingam, B., H. Jones, T. Reba, and J. Young. 2008. Exploring the science of complexity: ideas and implications for development and humanitarian efforts. Second edition. Working Paper 285. Overseas Development Institute, London, UK. [online] URL: https://www.odi.org/sites/odi.org.uk/files/odi-assets/publicationsopinion-files/833.pdf

Realising European Resilience for Critical Infrastructure (RESILENS). 2016. Deliverable D2.2: qualitative, semiquantitative and quantitative methods and measures for resilience assessment and enhancement: report and templates. Consortium for Realising European Resilience for Critical Infrastructure, Dublin, Ireland. [online] URL: http://resilens.eu/wp-content/ uploads/2016/08/D2.2-Methods-for-Resilience-Assessment-Final. pdf

Resilience Alliance. 2010. Assessing resilience in social-ecological systems: workbook for practitioners. Revised version 2.0. Resilience Alliance. [online] URL: http://www.reefresilience.org/ pdf/ResilienceAssessment2.pdf

Righi, A. W., T. A. Saurin, and P. Wachs. 2015. A systematic literature review of resilience engineering: research areas and a research agenda proposal. Reliability Engineering and System Safety 141:142-152. [online] URL: http://dx.doi.org/10.1016/j. ress.2015.03.007

Rinaldi, S. M., J. P. Peerenboom, and T. K. Kelly. 2001. Identifying, understanding, and analyzing critical infrastructure interdependencies. IEEE Control Systems 21(6):11-25. http://dx. doi.org/10.1109/37.969131

Rose, A., G. Oladosu, and S.-Y. Liao. 2007. Business interruption impacts of a terrorist attack on the electric power system of Los Angeles: customer resilience to a total blackout. Risk Analysis 27 (3):513-531. [online] URL: http://dx.doi.org/10.1111/ j.1539-6924.2007.00912.x

Rosen, R. 2000. Essays on life itself. Columbia University Press, New York, New York, USA.

Rumbaitis del Rio, C. 2015. When disasters strike twice. Rockefeller Foundation, New York, New York, USA. [online] URL: http://www.rockefellerfoundation.org/blog/when-disasters$\underline{\text { strike-twice/ }}$ 
Saurin, T. A., A. W. Righi, and É. Henriqson. 2013. Characteristics of complex socio-technical systems and guidelines for their management: the role of resilience. Pages 11-16 in I. Herrera, J. M. Schraagen, J. Van der Vorm, and D. Woods, editors. 5th symposium on resilience engineering: managing tradeoffs. Resilience Engineering Association, Soesterberg, The Netherlands.

Savonis, M. J., J. R. Potter, and C. B. Snow. 2014. Continuing challenges in transportation adaptation. Current Sustainablel Renewable Energy Reports 1(1):27-34. http://dx.doi.org/10.1007/ $\underline{\text { s40518-014-0004-7 }}$

Savulescu, S. C. 2014, editor. Real-time stability in power systems: techniques for early detection of the risk of blackout. Second edition. Springer, Cham, Switzerland.

Schneider, M., and M. Somers. 2006. Organizations as complex adaptive systems: implications of complexity theory for leadership research. Leadership Quarterly 17(4):351-365. http:// dx.doi.org/10.1016/j.leaqua.2006.04.006

Schulman, P., E. Roe, M. van Eeten, and M. de Bruijne. 2004. High reliability and the management of critical infrastructures. Journal of Contingencies and Crisis Management 12(1):14-28. http://dx.doi.org/10.1111/j.0966-0879.2004.01201003.x

Scientific and Technical Advisory Panel (STAP). 2015. Resilience adaptation transformation assessment and learning framework. STAP, Washington, D.C., USA. [online] URL: http://www. $\underline{\text { stapgef.org/sites/default/files/documents/Brief-on-Resilience-Adaptation- }}$ Transformation-Assessment-Learning-Framework-16-May-2015. pdf

Scolobig, A., T. Prior, D. Schröter, J. Jörin, and A. Patt. 2015. Towards people-centred approaches for effective disaster risk management: balancing rhetoric with reality. International Journal of Disaster Risk Reduction (12):202-212. https://doi. org/10.1016/j.ijdrr.2015.01.006

Seeliger, L., and I. Turok. 2014. Averting a downward spiral: building resilience in informal urban settlements through adaptive governance. Environment and Urbanization 26(1):184-199. http:// dx.doi.org/10.1177/0956247813516240

Seville, E., D. Van Opstal, and J. Vargo. 2015. A primer in resiliency: seven principles for managing the unexpected. Global Business and Organizational Excellence 34(3):6-18. [online] URL: http://dx.doi.org/10.1002/joe.21600

Shaw, D., J. Scully, and T. Hart. 2014. The paradox of social resilience: how cognitive strategies and coping mechanisms attenuate and accentuate resilience. Global Environmental Change 25:194-203. [online] URL: http://dx.doi.org/10.1016/j. gloenvcha.2014.01.006

Sheffi, Y. 2005. The resilient enterprise: overcoming vulnerability for competitive advantage. MIT Press, Cambridge, Massachusetts, USA.

Simone, R. C. 2014. Cascading failure in critical infrastructure: an actor-network analysis of the 1998 ice storm in Ottawa. Thesis, Carleton University, Ottawa, Canada. [online] URL: https:// curve.carleton.ca/7a8f5746-6aa4-4ec3-98d1-4681daaf82ff
Snowden, D. J., and M. E. Boone. 2007. A leader's framework for decision making. Harvard Business Review November 2007. [online] URL: https://hbr.org/2007/11/a-leaders-framework-fordecision-making

South African Bureau of Standards (SABS). 2010. NRS 048-9:2010. Electricity supply - quality of supply part 9: load reduction practices, system restoration practices, and critical load and essential load requirements under system emergencies. SABS, Pretoria, South Africa.

Stephenson, A. V. 2010. Benchmarking the resilience of organisations. Dissertation. University of Canterbury, Christchurch, New Zealand. [online] URL: http://hdl.handle.net/10092/5303

Stockton, P. 2014. Resilience for black sky days: supplementing reliability metrics for extraodinary and hazardous events. National Association of Regulatory Utility Commissioners, Washington, D.C., USA. [online] URL: http://www.sonecon.com/docs/ studies/Resilience for Black Sky Days Stockton Sonecon FINAL ONLINE Feb5.pdf

Terenzini, P. T. 1989. Assessment with open eyes: pitfalls in studying student outcomes. Journal of Higher Education 60 (6):644-664. http://dx.doi.org/10.1080/00221546.1989.11775076

Tversky, A., and D. Kahneman. 1974. Judgement under uncertainty: heuristics and biases. Science 185(4157):1124-1131. http://dx.doi.org/10.1126/science.185.4157.1124

United Nations Economic and Social Commission for Asia and the Pacific (UNESCAP). 2013. Building resilience to natural disasters and major economic crises. UNESCAP, Bangkok, Thailand.

United Nations Office for Disaster Risk Reduction (UNISDR). 2009. 2009 UNISDR terminology on disaster risk reduction. UNISDR, Geneva, Switzerland. [online] URL: https://www. unisdr.org/we/inform/publications/7817

United Nations Office for Disaster Risk Reduction (UNISDR). 2015. Sendai framework for disaster risk reduction 2015-2030. UNISDR, Geneva, Switzerland. [online] URL: https://www. unisdr.org/we/inform/publications/43291

U.S. Department of Energy (DOE). 2014. Smart grid investments improve grid reliability, resilience, and storm responses. U.S. Department of Energy, Washington, D.C., USA. [online] URL: https://energy.gov/sites/prod/files/2014/12/f19/SG-ImprovesRestorationNov2014.pdf

U.S. Department of Homeland Security (DHS). 2010. Quadrennial Homeland Security review report: a strategic framework for a secure homeland. U.S. Department of Homeland Security, Washington, D.C., USA. [online] URL: https://www. dhs.gov/xlibrary/assets/qhsr report.pdf

Varga, L. 2015. Guest editorial: complexity and sustainable utility services. Emergence: Complexity and Organization 17(2). [online] URL: https://journal.emergentpublications.com/article/editorial/

Viejo, P., J. Gonzalez de Durana, O. Barambones, F.-M. Hernández-Tejera, J. J. Hernandez, J. É. Gómez, and E. Kremers. 2015. Criticality in complex socio-technical systems: an empirical approach. Emergence: Complexity and Organization 17(2). [online] URL: https://journal.emergentpublications.com/article/ criticality-in-complex-socio-technical-systems/ 
Walker, B., S. Carpenter, J. Anderies, N. Abel, G. S. Cumming, M. Janssen, L. Lebel, J. Norberg, G. D. Peterson, and R. Pritchard. 2002. Resilience management in social-ecological systems: a working hypothesis for a participatory approach. Conservation Ecology 6(1):14. http://dx.doi.org/10.5751/ES-00356-060114

Walker, B., C. S. Holling, S. R. Carpenter, and A. Kinzig. 2004. Resilience, adaptability and transformability in social-ecological systems. Ecology and Society 9(2):5. http://dx.doi.org/10.5751/ ES-00650-090205

Walker, B., and D. Salt. 2006. Resilience thinking: sustaining ecosystems and people in a changing world. Island Press, Washington, D.C., USA.

Walker, B., and D. Salt. 2012. Resilience practice: building capacity to absorb disturbance and maintain function. Island Press, Washington, D.C., USA. http://dx.doi.org/10.5822/978-1-61091-231-0

Walker, B. H., N. Abel, J. M. Anderies, and P. Ryan. 2009. Resilience, adaptability, and transformability in the GoulburnBroken Catchment, Australia. Ecology and Society 14(1):12. http://dx.doi.org/10.5751/ES-02824-140112

Weichselgartner, J., and I. Kelman. 2015. Geographies of resilience: challenges and opportunities of a descriptive concept. Progress in Human Geography 39(3):249-267. http://dx.doi. org/10.1177/0309132513518834

Weick, K. E. 1995. Sensemaking in organizations. Sage, Thousand Oaks, California, USA.

Weick, K. E., and K. M. Sutcliffe. 2007. Managing the unexpected: resilient performance in an age of uncertainty. Second edition. Jossey-Bass, San Francisco, California, USA.

Weick, K. E., K. M. Sutcliffe, and D. Obstfeld. 1999. Organizing for high reliability: processes of collective mindfulness. Pages 81-123 in R. I. Sutton and B. M. Staw, editors. Research in organizational behavior. Volume 21. Jai, Amsterdam, The Netherlands.

Westley, F., B. Zimmerman, and M. Q. Patton. 2006. Getting to maybe: how the world is changed. Vintage Canada, Toronto, Canada.

Woods, D. D. 2005. Creating foresight: lessons for enhancing resilience from Columbia. Pages 289-308 in W. H. Starbuck and M. Farjoun, editors. Organization at the limit: lessons from the Columbia disaster. Blackwell, Malden, Massachusetts, USA.

Wybo, J.-L. 2008. The role of simulation exercises in the assessment of robustness and resilience of private or public organizations. Pages 491-507 in H. J. Pasman and I. A. Kirillov, editors. Resilience of cities to terrorist and other threats: learning from $9 / 11$ and further research issues. Springer, Dordrecht, The Netherlands. http://dx.doi.org/10.1007/978-1-4020-8489-8 23

Ye, Q. 2014. Building resilient power grids from integrated risk governance perspective: a lesson learned from China's 2008 icesnow storm disaster. European Physical Journal Special Topics 223(12):2439-2449. https://doi.org/10.1140/epjst/e2014-02218-7
Youssef, C. M., and F. Luthans. 2007. Positive organizational behavior in the workplace: the impact of hope, optimism, and resilience. Journal of Management 33(5):774-800. http://dx.doi. org/10.1177/0149206307305562

Zarakas, W. P., S. Sergici, H. Bishop, J. Zahniser-Word, and P. Fox-Penner. 2014. Utility investments in resiliency: balancing benefits with cost in an uncertain environment. Electricity Journal 27(5):31-41. http://dx.doi.org/10.1016/j.tej.2014.05.005

Zhao, K., A. Kumar, T. P. Harrison, and J. Yen. 2011. Analyzing the resilience of complex supply network topologies against random and targeted disruptions. IEEE Systems Journal 5 (1):28-39. http://dx.doi.org/10.1109/JSYST.2010.2100192

Zolli, A., and A. M. Healy. 2012. Resilience: why things bounce back? Simon and Schuster, New York, New York, USA. 